\title{
EL RÉGIMEN JURÍDICO DE LOS MEDIOS DE COMUNICACIÓN EN ALEMANIA
}

\author{
MÓNICA ARENAS RAMIRO \\ Profesora Contratada Doctora de Derecho Constitucional \\ Universidad de Alcalá
}

\section{SUMARIO}

I. Medios de comunicación, pluralismo y opinión pública libre.

II. La prensa.

III. La radio y la televisión.

IV. Los servicios telemedia.

V. Mecanismos de control.

\section{MEDIOS DE COMUNICACIÓN, PLURALISMO Y OPINIÓN PÚBLICA LIBRE}

Los avances tecnológicos, el desarrollo de Internet y la existencia de un mercado cada vez más globalizado, marcado por la convergencia digital de los medios, han provocado que las tradicionales reglas que venían rigiendo el mundo del audiovisual se muestren insuficientes, poniéndose en tela de juicio la finalidad última de los medios de comunicación, sus presupuestos constitucionales y, más concretamente, el mantenimiento y la financiación pública de los mismos ${ }^{1}$. Se

1 Sobre esta cuestión, vid. Humphreys, P., «El futuro de la radiodifusión pública en el Reino Unido y Alemania», en Infoamérica, n. ${ }^{\circ}$ 3-4, 2010, pp. $57-72$ (p. 58); y QuAdRA-SALCEDO, T. DE LA, «Informe preliminar sobre el régimen jurídico de lo audiovisual», en QuADRA-SALCEDO, T. DE LA, El régimen jurídico del audiovisual, Marcial Pons, Barcelona, 2000, pp. 17-19. Con más detalle sobre la dificultad de los Gobiernos por controlar el mercado global, vid. BARNETT, S., «Public service broadcasting: a manifesto for survival in the multimedia age», Paper delivered to the RIPE Conference in Amsterdam, noviembre 2006, pp. 2-3 (Disponible on line: http://ripeat.org/wp-content/uploads/2010/03/Barnett_final.pdf. Consultado: 6/07/2015). 
hace necesario encontrar un nuevo régimen que haga viables las libertades informativas que los medios de comunicación llevan inherentes ${ }^{2}$.

Para poder encontrar la respuesta adecuada a cuál es el mejor modelo de comunicación audiovisual en un Estado social y democrático es preciso analizar, en primer lugar, los presupuestos constitucionales que determinan el régimen jurídico de la radiotelevisión y, posteriormente, ver si la configuración que legislativamente se ha dado a dichos medios permite que los citados presupuestos se cumplan libre de todo tipo de injerencias ${ }^{3}$. En este punto, además, debemos partir de una idea básica y evidente: un Estado que se considera democrático debe proteger las llamadas libertades de la comunicación con el fin de garantizar la formación de una opinión pública libre, elemento esencial de su funcionamiento. El fin constitucionalmente establecido es claro: garantizar la libertad en el proceso de formación de la opinión pública. Y éste es el motivo esencial por el cual hemos elegido Alemania como referente y objeto de análisis.

El modelo de la radiotelevisión alemana es un referente, no tanto por el reconocimiento constitucional de los derechos y libertades de la comunicación — que en Europa es prácticamente semejante en todos los Estados—, sino por la forma en la que a través de la regulación de los medios de comunicación se garantiza el valor del pluralismo ${ }^{4}$. Asimismo, la configuración del modelo audiovisual que ha venido desarrollando el Tribunal Constitucional federal alemán (Bundesverfassungsgericht, $B \operatorname{Verf} G$ ) —a través de una serie de sentencias (unas catorce) conocidas como «sentencias de la radiotelevisión»-, es digna de elogio5. A la hora de diseñar el régimen radiotelevisivo en Alemania, en este país más que en ningún otro, la interpretación que el Tribunal Constitucional federal ha realizado sobre los derechos fundamentales y, en concreto, sobre los relacionados con las

2 Sobre esta cuestión, en relación con el modelo alemán analizado, vid. LENT, W., Rundfunk-, Medien-, Teledienste, Peter Lang, Frankfurt, 2001, pp. 29 y 159; Degenhart, CH., Der Funktionsauftrag des öffentlich-rechtlichen Rundfunks in der digitalen Welt, K\&R, Heidelberg, 2001, p. 55 y ss.; GERsDORF, H., Grundzüge des Rundfunkrechts, Beck, Munich, 2003, p. 36; ScHulz, W., «Kommentierung zu §§ 2, 52, 53 RStV», en Hahn, W./Vesting, TH., Beck'scher Kommentar zum Rundfunkrecht, 2. ${ }^{a}$ ed., Beck, Munich, 2008; y WaLdenBerger, A., «Presserecht im Internet und «elektronische Presse»", en SPINDler, G./Schuster, F., Recht der elektronischen Medien. Kommentar, $1 .^{\text {a }}$ ed., Beck, Munich, 2008, pp. 421-452.

3 SAlvador Martínez, M., «El modelo audiovisual alemán», en QuAdra-Salcedo, T. DE LA, El régimen jurídico del audiovisual, Marcial Pons, Barcelona, 2000, p. 365 (pp. 365-378).

4 GonZÁlez EnCINAR, J.J., «Modelos comparados de regulación de lo audiovisual», en QuAdra-SALCEDO, T. DE LA, El régimen jurídico del audiovisual, Marcial Pons, Barcelona, 2000, p. 97 (pp. 95-109).

5 Estas sentencias son: la 1. a , de 28 de febrero de 1961 (BVerfGE 12, 205); la 2. a, de 27 de julio de 1971 (BVerfGE 31, 314); la 3. a, de 16 de junio 1981 (BVerfGE 57, 295); la 4. ${ }^{\text {a }}$, de 4 de noviembre de 1986 (BVerfGE 73, 118); la 5.a, de 24 de marzo de 1987 (BVerfGE 74, 297); la 6.. , de 5 de febrero de 1991 (BVerfGE 83, 238); la 7. a, de 6 de octubre de 1992 (BVerfGE 87, 181); la 8. ${ }^{\text {a }}$, de 22 de febrero de 1994 (BVerfGE 90, 60); la 9. ${ }^{\text {, }}$, de 22 de febrero de 1995 (BVerfGE 92, 203); la 10. a, de 17 de febrero de 1998 (BVerfGE 97, 228); la 11. a , de 20 de febrero de 1998 (BVerfGE 97, 298); la 12. ${ }^{\text {, }}$, de 11 de septiembre de 2007 (BVerfGE 119, 181); la 13. ${ }^{\text {a }}$, de 12 de marzo de 2008 (BVerfGE 121, 30); y la 14. a, de 25 de marzo de 2014 (1 BvF 1/11). Destacando el papel del BVerfG, vid. también KLOTZ, F., «The Radio and Television System in Germany», en Radio and Television Systems in Europe 2000/2001, 2000, pp. 123 a 137. 
libertades informativas, ha marcado las pautas a seguir, confirmando, desarrollando, e incluso, matizando, los principios inspiradores del mismo ${ }^{6}$.

En esta línea, la interpretación que el $B V \operatorname{erf} G$ ha hecho del artículo 5.1 de la Ley Fundamental (Grundgesetz für die Bundesrepublik Deutschland, $G G)^{7}$, artículo relativo a la «libertad de los medios de comunicación», ha venido a confirmar que la libertad de información a través de los medios de comunicación tiene una entidad diferenciada de la propia de esta libertad: en relación con los medios de comunicación se convierte en una «libertad al servicio de una función», la propia de los medios de comunicación, esto es, garantizar y proteger la formación de una opinión pública libre ${ }^{8}$. Asimismo, el modelo alemán, al considerar la misión de la televisión pública como un «servicio esencial», donde además de las funciones de informar y formar, debe buscar entretener, refuerza el principio de pluralismo, posibilitando que la televisión pública pueda llegar a todos los sectores sociales, incluido aquél que busca en la televisión, esencialmente, una función de entretenimiento9 . En el caso de Alemania, el concepto de servicio público se caracteriza, además de por obedecer a un mandato constitucional, por tres elementos: un medio técnico de transmisión que asegura a todos los ciudadanos la recepción de los programas televisivos; una programación que se corresponde, por su objeto y por el tipo de programa, con el mandato de informar, formar y entretener; y por el valor del pluralismo y equilibrio en la programación, que se garantizan, sobre todo, a través de normas de organización y procedimiento ${ }^{10}$. Hay que señalar que la prestación del servicio esencial de la televisión en el sistema dual alemán, tal y como ha mantenido el $B V \operatorname{erf} G$, es competencia en primer lugar de la televisión pública y, como complemento, también de la televisión privada, aunque esta última tiene mayor autonomía para decidir qué emite y cómo lo hace ${ }^{11}$. Mientras que la pública presta básicamente dicho servicio, la privada, en cuanto concesio-

6 Vid. Hoffmann-Riem, W./Schulz, W., «La televisión pública en Alemania», en GonZÁlez ENCINAR, J.J. (ed.), La libertad de la televisión pública en la Unión Europea, CEDECS, Madrid, 1996, p. 61; y SALvador Mártínez, M., La libertad de la televisión, CEDECS, Madrid, 1998, p. 125 y ss.

7 Art. 5.1 GG: «Toda persona tiene el derecho a expresar y difundir libremente su opinión oralmente, por escrito $y$ a través de la imagen, $y$ de informarse sin trabas en fuentes accesibles a todos. La libertad de prensa y la libertad de información por radio, televisión y cinematografía serán garantizadas. La censura está probibida».

8 Sobre esta afirmación, vid. las BVerfGE 57, 297 (319); y también BVerfGE 73, 118 (152); y 74, 297 (323), donde el BVerfG hace titulares de este derecho a las propias radiotelevisiones públicas y privadas.

9 Quadra-SAlCEDO, T. DE LA, «Informe preliminar...», op. cit., pp. 34-37. En la «cuarta» BVerfGE 73,118 , de 4 de noviembre de 1986, el BVerfG concluyó que correspondía a la radiotelevisión pública cumplir con la finalidad del servicio esencial de televisión, por lo que además de su papel en la formación de una opinión social, entretener e informar, también se incluía su responsabilidad cultural.

10 Dicho concepto se inspira en el tradicional concepto de servicio público británico, aunque se diferencia de éste en la estructura organizativa, ya que los responsables de las radiotelevisiones públicas alemanas no son nombrados ni por el Gobierno ni por el Parlamento. Vid. Salvador MarTínez, M., «El modelo audiovisual...», op. cit., p. 368; y GonZÁLEZ EnCINAR, J.J., «Modelos comparados...», op. cit., pp. 100-101.

11 BVerfGE 73, 118 (158-159); y BVerfGE 74, 324, donde el BVerfG entendió que se debía ofrecer un servicio básico, informando sobre todos los acontecimientos con relevancia social, garantizando en la programación la diversidad cultural y de opiniones que integran la sociedad. Con esta idea también, vid. Voss, 
naria de un servicio público, queda sujeta al cumplimiento de normas de programación $^{12}$.

La libertad de los medios ha sido concretada aún más por el $B V \operatorname{verf}$ que ha matizado que lo que se protege es la actividad del medio de comunicación, su programación frente a cualquier tipo de influencia de los poderes públicos ${ }^{13}$, por lo que la emisión de cualquier programa debe estar protegida sólo y en la medida en que la misma contribuya a la garantía de la formación de una opinión pública libre $^{14}$. De esta forma, para poder hacer efectiva dicha libertad y cumplir con el citado objetivo, el Tribunal Constitucional federal también ha concluido que el legislador debe desarrollar el derecho fundamental no sólo con normas materiales, sino también con normas de organización y procedimiento. Dichas normas van dirigidas, por un lado, a garantizar la emisión de una programación variada y plural - para lo cual debe existir un órgano formado por representantes de los grupos sociales más relevantes, que sea el que se encargue de confeccionar y vigilar los contenidos de la misma-y, por otro lado, a garantizar la independencia orgánica y financiera del medio de comunicación frente al Estado ${ }^{15}$. La finalidad de las normas de organización es hacer posible que el medio de comunicación cumpla con su misión sin ningún tipo de interferencia ${ }^{16}$.

El desarrollo legal de la libertad de los medios de comunicación se va a plasmar en las Leyes de los medios de comunicación y, esencialmente, en el denominado Acuerdo Federal sobre Radiodiotelevisión y Telemedia (Staatsvertrag für Rundfunk und Telemedien, conocido como «Rundfunkstaatsvertrag» o RStV $)^{17}$. Aquí también se ha manifestado el $B V \operatorname{erf} G$ para señalar que si bien el concepto de radiodifusión no está definido en la Ley Fundamental $(G G)$ y es el citado $R S t V$ el que la define, el mismo debe interpretarse conforme a las directrices constitucio-

J.M., Pluraler Rundfunk in Europa. Ein duales System für Europa?, Peter Lang Verlag, Frankfurt, 2008, p. 61; y PoptcheVA, E.V., «Las autoridades independientes...», op. cit., p. 290.

$12 \S 3.1 R S t V$; y BVerfGE 57, 295 (325); y 73, 118 (161). El problema surge porque al tener la misma misión se condiciona la forma de financiación, y porque dicha emisión debe ser interpretada a la luz del cambio experimentado por el sector audiovisual. Al respecto, vid. Hermann, K., «Der öffentlich-rechtliche Rundfunk in Deutschland», en DSI, sept. 2013.

13 BVerfGE 12, 205 (260); 31, 314 (329); 57, 295 (320); 74, 297 (324).

14 BVerfGE 57, 295 (323). Al respecto, vid., también, BVerfGE 87, 181 (179). Y, por todos, sobre la dimensión objetiva de la libertad de los medios de comunicación, vid. la «sexta» BVerfGE 83, 238. Sobre esta cuestión, vid. Hesse, A., Rundfunkrecht, 3. a ed., Vahlen, Munich, 2003, pp. 117 y ss.; y sobre el doble contenido, subjetivo y objetivo, vid. SAlvador Martínez, M., «El modelo audiovisual...», op. cit., pp. 369-372.

15 Salvador Martínez, M., La libertad de..., op. cit., p. 192 y ss.

16 En este sentido, el $B \operatorname{Verf} G$ ha considerado que el derecho fundamental consagrado en el artículo 5.1 $G G$ incluye también una libertad de organización del ente o institución, pública o privada, de radiotelevisión. En este sentido, vid. GonZÁlez EnCINAR, J.J., «Modelos comparados...», op. cit., p. 99, para quien esto refleja el estar ante «una institución al servicio de una función». Por todos, vid., también, STARCK, CH., «Rundfunkfreiheit als Organisationsproblem», en Recht und Staat, n. ${ }^{\circ} 422 / 423,1973$, p. 5 y ss.

17 Decimoquinto Acuerdo Federal para la modificación del Acuedo Federal de Radiotelevisión y Telemedia, del 15 al 21 de diciembre de 2010, con entrada en vigor el 1 de enero de 2013. 
nales y no al revés ${ }^{18}$. La idea parece clara: se debe regular el régimen audiovisual para garantizar el pluralismo y que los ciudadanos puedan formarse una opinión pública libre, participar en asuntos públicos con razón de causa y conseguir así un Estado más democrático. No podemos negar ni olvidar que esta formación de la opinión pública es determinante, especialmente, cuando estamos hablando de la formación de una voluntad política que se plasmará, posteriormente, en el ejercicio del derecho de sufragio activo y pasivo de los ciudadanos receptores de la información ${ }^{19}$. En el ordenamiento jurídico alemán esta idea ha estado clara desde un principio: no se puede garantizar la libre formación de una opinión pública si no se garantiza esa libertad también frente a los poderes del Estado y, en consecuencia, es necesario exigir total libertad en los procesos de comunicación ${ }^{20}$.

Consecuentemente, para el desarrollo legal del modelo audiovisual alemán, el Tribunal Constitucional federal ha intervenido nuevamente para concretarlo aún más y ha entendido que al ser la televisión el medio de comunicación social que más influencia tiene en el proceso de formación de una opinión pública y, por tanto, el que más influencia tiene en el funcionamiento de un Estado democráti$\mathrm{CO}^{21}$, dicho medio de comunicación debería tener una regulación específica, diferente de la exigida para el resto de los medios de comunicación ${ }^{22}$. En este sentido, se va a controlar que la organización de la televisión no quede en manos del Estado ni en manos de un único o un determinado grupo social, y en concreto de un partido político ${ }^{23}$. Así, por ejemplo, el $B V e r f G$ ha dejado claro que, a pesar de la presencia de representantes de los partidos políticos en los órganos de gobierno y dirección de los medios de comunicación — garantizándose así el pluralismo-, la influencia de los mismos debe verse en todo caso limitada ${ }^{24}$.

Los principios constitucionales que rigen el modelo audiovisual alemán parecen contradictorios pues, por un lado nos indican la obligación del Estado de desarrollar su régimen jurídico, pero, por otro lado, se limita su intervención y participación en el mismo ${ }^{25}$. Pero esto no es contradictorio. En el caso de Alemania, la preocupación por regular el régimen jurídico del audiovisual va más allá de la

18 Al respecto, vid. la «cuarta» BVerfGE 73, 118, de 4 de noviembre de 1986; así como la «quinta» BVerfGE 74, 297, de 24 de marzo de 1987, donde el BVerfG señala que el concepto de radiodifusión previsto en el texto constitucional debe entenderse en un sentido amplio y dinámico, incluyendo los servicios en línea.

19 La participación de los partidos políticos debe verse sometida a unas reglas particulares de juego, conforme a las cuales se puedan garantizar el pluralismo y el libre proceso de formación de la voluntad política. Al respecto, haciendo referencia al concepto de «igualdad de oportunidades» ( Chancengleicheit»), vid. FernandeZ Vivas, Y., Igualdad y partidos políticos, Congreso de los Diputados, Madrid, 2007, pp. 454 y 457.

20 SAlvador Martínez, M., «El modelo audiovisual...», op. cit., p. 369; y GonZÁlez EnCINAR, J.J., «Televisión y democracia», en Anuario de Derecho Constitucional y Parlamentario, n. ${ }^{\circ}$ 7, 1995, p. 154 y ss.

21 Vid. GonzÁlez Encinar, J.J., «Televisión y democracia», op. cit., p. 143 y ss.

22 Vid. BVerfGE 12, 205 (261); 31, 314 (326); y 57, 295 (322-323). Y, también, Salvador MartíNEZ, M., «El modelo audiovisual...», op. cit., p. 368.

23 BVerfGE 12, 205 (262); y 1 BvF 1/11.

24 La ya citada $1 \mathrm{BvF} 1 / 11$.

25 Hoffmann-Riem, W./Schulz, W., «La televisión pública...», op. cit., p. 68. 
mera preocupación por encontrar el modelo más o menos eficaz de gestión de los medios de comunicación y enlaza directamente con la preocupación de hacer efectiva la democracia. Desde la segunda mitad del siglo xx, el objetivo de este país es que «la democracia debe de penetrar en la sociedad misma para evitar la catástrofe del nazismo y de la IIGM». Por este motivo, con la promulgación de la Ley Fundamental en 1949, en lo relacionado con los medios de comunicación, se refuerza la participación de los ciudadanos y de los grupos sociales de todas las ideologías en los medios de difusión, garantizando así el pluralismo social, económico y político existente. Se quiere evitar la propaganda y la manipulación de los medios ${ }^{26}$. Para comprobar si los medios de comunicación son o no manipulables se hace necesario analizar cómo se han organizado los mismos, esto es, cómo se ha configurado su organización y funcionamiento interno, o su régimen financiero.

No obstante, aún teniendo claro que el modelo alemán es un ejemplo de defensa del pluralismo, no podemos tampoco negar que después de 1949, los partidos políticos alemanes han intentado ampliar su influencia sobre la radiotelevisión, ya fuera sobre la pública (cuando era la única existente durante el monopolio), ya sea sobre pública y privada, tras su apertura. A pesar de estos intentos, el Tribunal Constitucional federal alemán ha realizado una importante labor defendiendo la libertad de los medios frente a los poderes públicos y, especialmente, frente a los partidos políticos que dominan los órganos del Estado ${ }^{27}$.

Por último, para entender la peculiaridad del modelo alemán no podemos olvidar la estructura federal del Estado ${ }^{28}$. En este sentido hay que señalar que las competencias en materia de radiotelevisión las tienen los Estados (Länder), correspondiéndole a la Federación (Bund), exclusivamente, la ordenación técnica de las telecomunicaciones y algunas competencias menores. Así lo estableció el $B V \operatorname{erf} G$ en la primera de sus sentencias sobre la libertad de los medios de comunicación ${ }^{29}$. Sin detenernos demasiado sobre esta cuestión, sí que debemos reiterar aquí que son los legisladores de los Länder los que tienen la competencias para crear los organismos reguladores de la radiotelevisión ${ }^{30}$, correspondiendo a la Fe-

26 Quadra-Salcedo, T. DE LA, «Informe preliminar...», op. cit., p. 17. Y en el mismo sentido, PoptCHEva, E.V., «Las autoridades independientes de control de los medios de comunicación audiovisual en Alemania», en GAVARA DE CARA, J.C. (ed.), Las autoridades independientes de control de los medios de comunicación audiovisual, Bosch, Barcelona, 2013, pp. 289-290 (pp. 289-314).

27 GonzÁlez Encinar, J.J., «Modelos comparados...», op. cit., p. 98. Así, la «decimocuarta» BVerfGE (1 BvF 1/11, de 25 de marzo de 2014) ha exigido la limitación de la influencia de los partidos políticos en los medios y ha concluido que «la televisión pública no puede convertirse en una televisión estatal, sino que tiene que representar toda la variedad de opiniones que hay en la sociedad». Sobre la misma, vid. SÁNCHEZ, R., «El Constitucional alemán limita la presencia de políticos en la dirección de la televisión pública», en Cuadernos de Periodistas, n. ${ }^{\circ}$ 28, 2014, pp. 27-32.

28 Sobre esta cuestión, vid. RüTER, K., «Föderalismus als Organisationsprinzip des öffentlich-rechtlichen Rundfunks in Deutschland», en Arbeitspapiere des Instituts für Rundfunkökonomie an der Universität zu Köln, Heft 93, 1998, pp. 1-7.

29 Nos referimos a la BVerfGE 12, 205, de 28 de febrero de 1961.

30 Art. 70 GG, en función de la cláusula residual (art. 30 GG). Vid., también BVerfGE 12, 205. 
deración las cuestiones técnicas de las telecomunicaciones, es decir, aquellas cuestiones relacionadas con las herramientas técnicas para su emisión ${ }^{31}$. No obstante, el $B V \operatorname{erf} G$ ha reconocido que la Federación, en ejercicio de la competencia que tiene atribuida sobre asuntos exteriores, puede crear una Institución de Radiotelevisión siempre y cuando ésta emita sólo para el extranjero, lo cual se cumple en la actualidad a través de la Deutsche Welle $(D W)^{32}$.

\section{LA PRENSA}

\section{Régimen jurídico}

Alemania es el mercado de prensa más importante de Europa, y el quinto de todo el mundo. Se consume una media de casi diecisiete millones de prensa diaria y cinco millones de periódicos semanales y dominicales ${ }^{33}$. Así las cosas, el régimen de la prensa en Alemania, como en la mayoría de los Estados europeos, se rige por el principio de libertad, esto es, las empresas editoras no están sujetas a una previa o posterior licencia para el ejercicio de su actividad ${ }^{34}$. Aunque, como es lógico, deben someterse a una serie de reglas de respeto del resto de derechos fundamentales, prohibiéndose todo tipo de censura ${ }^{35}$.

En el año 1974, con el fin de crear un marco común para la prensa, a nivel federal se propuso la aprobación de una ley marco, la Presserechtsrabmengesetz ${ }^{36}$. No obstante, la competencia legislativa de los Länder en la materia - como sucede con la radio y la televisión- ${ }^{37}$, hizo considerar que dicha propuesta era del todo ineficaz, máxime cuando, incluso elaborando cada Land su propia norma, las Leyes de prensa son prácticamente idénticas y se diferencian en detalles mínimos ${ }^{38}$,

31 Art. 73.(1).7 GG en relación con el art. 87.f) GG. Vid. CARrillo López, M., «Las televisiones públicas en el Estado compuesto», en Quadra-SALCEDO, T. DE LA, El régimen jurídico del audiovisual, Marcial Pons, Barcelona, 2000, pp. 226-227 (pp. 225-242).

32 Así lo dejó dicho en la BVerfGE 12, 205 (225 y ss.), en un caso relacionado con la apliación de la Directiva «Televisión sin fronteras» de 1989 (Directiva 89/552/CEE), destacando la intervención de la Federación como una simple mandataria de sus Estados. Vid. Doyle, G., «Economía audiovisual: los medios audiovisuales en la Unión Europea», en Quaderns del CAC, n. ${ }^{\circ} 38,2012$, pp. 18-19 (pp. 15-24); WHEELER, M., «Whither Media Diversity», en SARIKakis, K. (ed.), Media and cultural policy in the UE, Rodopi, Amsterdam, 2007, pp. 227-249; y CARrillo LóPEZ, M., «Las televisiones públicas...», op. cit., pp. 225-226.

33 Datos extraídos de la Asociación Federal Alemana de Editores de Periódicos (Bundesverband Deutscher Zeitungsverleger): «Die deutschen Zeitungen in Zahlen und Daten 2015» (Disponible en http://www. bdzv.de/fileadmin/bdzv_hauptseite/aktuell/publikationen/2014/assets/Zahlen_Daten_2015.pdf. (Consultado: 6/07/2015))

34 Art. 5.2 GG; y, por ejemplo, § 2 BbgPG y $§ 2$ Berliner Pressegesetz.

35 Vid., por ejemplo, § $14 S M G$; y $§ 1$.(2) SächsPresseG.

36 Sobre la necesidad de una Ley federal sobre la prensa, vid. KoTYNEK, M., «Auftrag Klarheit. Warum der Bund jetzt ein Pressegesetz erlassen muss", en Die Zeit, n. ${ }^{\circ}$ 10/2013, de 28 de febrero de 2013.

37 Art. 75.2 GG.

38 Así, nos encontramos con 16 Leyes estatales, una por cada Länder: la Landespressegesetz Baden-Württemberg, de 14 de enero de 1964 (modificada por última vez el 29 de julio de 2014); la Bayerisches Pressegesetz 
destacando el hecho de que en todas ellas se recoge la función pública que desempeña la prensa a la hora de formar una opinión pública libre ${ }^{39}$.

Mientras que la regulación básica de la radio y la televisión se va a encontrar en el ya citado Rundfunkstaatsvertrag $(R S t V)$, la prensa tendrá sus principios de actuación en las respectivas Leyes estatales, así como en el conocido Código de la Prensa (Pressekodex), aprobado por el Consejo de la Prensa $(\text { Presserat })^{40}$. El Pressekodex es un conjunto de normas éticas (unas dieciséis Directrices ( $Z$ iffern)) destinadas a guiar la labor periodística con el fin de conseguir una conducta apropiada e independiente, por lo que incluye referencias al respeto a la verdad, a la diligencia debida en las investigaciones realizadas y el respeto a los derechos fundamentales.

La mayoría de las editoriales alemanas, adheridas al Código de la Prensa, también se comprometen a respetar la normativa de protección de datos persona$\operatorname{les}^{41} ; \mathrm{y}$, al mismo tiempo, asumiendo los principios del citado Código, a publicar las denuncias que puedan haber recibido por parte del Consejo de la Prensa.

\section{Organización interna}

Las empresas encargadas de dar el servicio público de prensa escrita, más allá de su estructura empresarial o de la forma privada que adopten, se caracterizan por sus integrantes, diferenciándose entre editores y redactores, además de los periodis-

(BayPrG), de 3 de octubre de 1949, en la redacción de 19 de abril de 2000 (modificada por última vez el 22 de julio de 2014); la Berliner Pressegesetz, de 15 de junio de 1965 (modificada por última vez el 18 de noviembre de 2009); la Brandenburgisches Landespressegesetz (BbgPG), de 13 de mayo de 1993 (modificada por última vez el 21 de junio de 2012); la Pressegesetz Bremen, de 16 de marzo de 1965 (modificada por última vez el 24 de enero de 2012); la Hamburgisches Pressegezt, de 29 de junio de 1965 (modificada por última vez el 15 de diciembre de 2009); la Hessisches Gesetz über Freibeit und Recht der Presse (Hessisches Pressegesetz, HPresseG), de 20 de noviembre de 1958, en la redacción de 12 de diciembre de 2003 (modificada por última vez el 13 de diciembre de 2012); la Landespressegesetz für das Land Mecklenburg-Vorpommern ( $\operatorname{Pr} G M-V$ ), de 6 de junio de 1993 (modificada por última vez el 17 de diciembre de 2009); la Niedersächsisches Pressegesetz, de 22 de marzo de 1965 (modificada por última vez el 11 de octubre de 2010); la Landespressegesetz Nordrhein-Westfalen (NRW), de 24 de mayo de 1966 (modificada por última vez el 3 de diciembre de 2013); la Landesmediengesetz Rheinland-Pfalz (LMG), de 4 de febrero de 2005 (esta Ley comprende las prescripciones de la derogada Pressegesetz Rheinland-Pfalz de 14 de junio de 1965, $\$ \S 13$ a 15 . Modificada por última vez el 3 de diciembre de 2014); la Saarländisches Mediengesetz (SMG), de 27 de febrero de 2002 (modificada por última vez el 22 de abril de 2013), §§ 13 y 14; la Sächsisches Gesetz über die Presse (SächsPresseG), de 3 de abril de 1991 (modificada por última vez el 6 de septiembre de 2009); la Pressegetz für das Land Sachsen-Anhalt, de 14 de agosto de 1991, en la redacción de 2 de mayo de 2013); la Landespressegesetz Schleswig-Holstein, de 19 de junio de 1964, en la redacción de 31 de enero de 2005 (modificada por última vez el 25 de enero de 2012); y la Thüringer Pressegesetz (TPG), de 31 de julio de 1991 (modificada por última vez el 16 de julio de 2008).

39 Vid., por ejemplo, §4 NRW; ó § 3 SächsPresseG.

40 Aprobado por primera vez el 12 de diciembre de 1973. Redacción actual de 11 de marzo de 2015

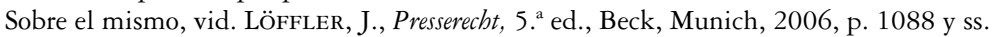

41 La mayoría de las empresas del sector están adheridas al mismo, aunque en el caso de Hamburgo, su proia Ley de prensa señala que, al estar prohibida la colegiación obligatoria a Asociaciones de prensa, existe un control estatal (\$ 1.(4) Hamburgisches Pressegezt). 
tas. En las Leyes de prensa (o de medios de comunicación que recogen las previsiones correspondientes a este medio de comunicación) se detalla el papel de cada uno, así como, especialmente, su régimen de responsabilidad y su independencia ${ }^{42}$.

La polémica generada en este medio de comunicación gira en torno a las publicaciones presentadas en Internet, esto es, la prensa electrónica. La cuestión surge por su consideración o no como medio de comunicación al publicarse en Internet, como la radiodifusión, con la aplicación de su régimen jurídico, o su consideración como prensa escrita y su regulación más liberal ${ }^{43}$. En relación con este tema, a finales de julio de 2008 un conjunto de editores aprobaron la conocida como «Declaración de Munich» («Münchner Erklärung»), solicitando que se limitara a las principales cadenas públicas la emisión por Internet de sonidos e imágenes en movimiento. La prensa escrita consideraba que no deberían emplear Internet para sus emisiones, pues suponía una clara amenaza para su existencia ${ }^{44}$.

\section{Contenido}

En cuanto a la programación o contenido de lo que se publica, son los propios autores o el editor los que responden del citado contenido, aunque alguna norma estatal también prevé la posibilidad de una responsabilidad penal indirecta para el caso de que lo publicado constituya un delito ${ }^{45}$.

Los periodistas, que gozan de una presunción de veracidad (especialmente para proteger a sus fuentes de información) ${ }^{46}$, deben adoptar la debida diligencia a la hora de comprobar el origen y la veracidad de sus noticias, dejando claro lo que representa una opinión personal de lo que es la noticia en sí ${ }^{47}$, máxime cuando puede existir algún conflicto con otros derechos fundamentales ${ }^{48}$.

42 Entre muchas otras, vid., por ejemplo, la Berliner Pressegesetz; y, también, LöHnER, E.M., «Der verantwortliche Redakteur», en Löffler, M., Presserecht, 5. ${ }^{a}$ ed., Beck, Munich, 2006, pp. 535-573.

43 Por prensa se entiende, de las Leyes de prensa de los Länder, aquel material impreso que aparece una vez o periódicamente, al margen de su contenido, precio o calidad. Sobre la definición de prensa, vid. § 7 LPG; y LöHner, E.M., «Druckwerke», en Löffler, M., Presserecht, 5. ${ }^{a}$ ed., Beck, Munich, 2006, pp. 455-486.

44 Disponible en http:/www.axelspringer.de/downloads/21/31430/muenchner_erklaerung.pdf (Consultado: 6/07/2015). Al respecto, vid. § 54.(2) RStV.

45 Vid., por ejemplo, $\S 19$ y 20 de la ya citada Ley de Prensa de Hamburgo (la Hamburgisches Pressegesetz).

46 Curiosamente este deber de secreto no se les aplica a los datos de conexión de sus teléfonos. Esta cuestión ha recibido numerosas críticas, pues choca frontalmente con la prohibición de confiscación del material periodístico existente en el $\$ 97.5$ del Código de Procedimiento Penal (Strafprozessordnung, StPO), de 12 de septiembre de 1950 (modificada por última vez el 27 de julio de 2015). Sobre esta cuestión y en relación con el privilegio probatorio (Zeugnisverweigerungsrecht), vid. también $\S 53 .(1) .5$ y $§ 100$ StPO.

$47 \mathrm{Al}$ respecto, vid. STeffen, E. «Sorgfaltspflicht der Presse», en Löffler, M., Presserecht, 5. ${ }^{a}$ ed., Beck, Munich, 2006, pp. 232-455 (párrafos 153 y ss.).

48 En estos casos, la regla general es que cuanto mayor sea el interés público en un determinado evento, la ponderación de intereses suele jugar a favor de la libertad de expresión. Al respecto, vid. STEFFEN, E. «Sorgfaltspflicht der Presse», op. cit., pp. 232-455 (párrafos 38 y 54). 


\section{Financiación}

En relación con la financiación de la prensa, debemos señalar que no se financiará de la misma manera que la radio y la televisión, pues no existe una cuota o contribución a la misma, sino que sus fuentes de financiación serán, básicamente, los pagos por las compras de los periódicos o abonos —el cliente paga por un producto-, así como los ingresos por publicidad ${ }^{49}$. La proporción de los ingresos por publicidad es muy diferente y depende sobre todo de la revista o periódico, y del público al que vaya dirigido, aunque esto influye más en las revistas que en los diarios, que, por regla general, no tienen un sector de lectores definido (con la excepción de algunos periódicos nacionales como el «Süddeutsche Zeitung» y «Frankfurter Allgemeine Zeitung»). La aparición de Internet alteró las ventas de espacios publicitarios de la prensa escrita, por lo que en los últimos años, los editores en Alemania han intentado compensar esta pérdida de ingresos a través del aumento de los precios de venta y de suscripción ${ }^{50}$, y se han planteado nuevas formas de financiación, como los suplementos culturales, gastronómicos o de moda, o su participación en las redes sociales ${ }^{51}$. No obstante, en algún caso excepcional la prensa también ha recibido subvenciones o ayudas públicas cuando su objetivo era la publicación de noticias relativas a los poderes públicos ${ }^{52}$.

\section{LA RADIO Y LA TELEVISIÓN}

\section{Régimen jurídico}

Si bien la radio comenzó a emitir en 1923, la televisión comenzó a emitir en Alemania unos diez años más tarde, siendo ambas el ejemplo más claro de manipulación de los medios de comunicación, al convertirlos el Gobierno en un instrumento de propaganda política, al ser conscientes de su importancia no sólo cultural, sino también política ${ }^{53}$. Por este motivo, tras la IIGM, el objetivo principal de Alemania se convirtió en garantizar la independencia y la neutralidad política de la

49 Gadringer, S./Kweton, S./Trappel, J./Vieth, T. (eds.), Journalismus und Werbung: Kommerzielle Grenzen der redaktionellen Autonomie, Springer, Wiesbaden, 2012, pp. 68-70.

50 En general, sobre la forma de financiación de los medios impresos, con un excelente gráfico que lo describe, vid. RöPER, H., "Zeitungsfinanzierung», en Bundeszentrale für politische Bildung, de 5 de septiembre de 2012. Disponible on line en http://www.bpb.de/gesellschaft/medien/lokaljournalismus/151250/zeitungsfinanzierung (Consultado: 6/08/2015).

51 Kramp, L., «Alternative Finanzierungsmodelle», en Bundeszentrale für politische Bildung, de 19 de enero de 2012. Disponible on line en http://www.bpb.de/gesellschaft/medien/lokaljournalismus/151251/alternative-finanzierung (Consultado: 6/08/2015).

52 Al respecto, vid. Gadringer, S./Kweton, S./Trappel, J./Vieth, T. (eds.), Journalismus und Werbung: ..., op. cit., pp. 68-70.

53 Diller, A., «Rundfunk in Dritten Reich», en Rundfunk in Deutschland, Vol. 2, 1980; y HofFMANN-RIEM, W./SchulZ, W., «La televisión pública...», op. cit., pp. 59-60. 
televisión para poder asegurar así el pluralismo y la libertad en el proceso de formación de la opinión pública ${ }^{54}$. Asimismo, en ese momento, si bien el régimen televisivo comenzó organizado en forma de monopolio, desde los años 80 se consolidó el sistema dual en Alemania ${ }^{55}$, lo que se vió reforzado, aún más si cabe, con la entrada de la televisión digital, que permitió ampliar la oferta de canales (especialmente en el terreno privado $)^{56}$. La decisión gira en torno a «si la televisión pública va a poder resistir al embate de los poderosos grupos de comunicación que compiten por el mercado y por la audiencia de las televisiones» ${ }^{57}$, pues la televisión pública debe existir como contrapunto al poder del mercado, evitando que el sistema de comunicación en una democracia dependa sólo de los avatares del mercado, cada vez más globalizado ${ }^{58}$. A partir de ese momento, el sistema de la radiotelevisión en Alemania está configurado en el sector público por las Instituciones de Radiotelevisión o «Rundfunkrechtanstalten» (radiotelevisiones públicas) y, en el sector privado, por las Instituciones de los Medios o "Landesmedienanstalten ${ }^{59}$. En relación con este sistema dual, el Tribunal Constitucional federal afirmó, por un lado, respecto de las televisiones públicas, que el legislador debería crear una Institución independiente del Estado que reflejara en su composición el pluralismo de la sociedad y que permitiera a los grupos sociales más relevantes participar en las decisiones relativas a la programación ${ }^{60} ; \mathrm{y}$, por otro lado, respecto de la televisión privada, el Tribunal señaló que el legislador debería establecer un mercado regulado y asegurarse de que la programación de las empresas privadas fuera, en la mayor medida posible, plural y equilibra$\mathrm{da}^{61}$. «El sistema conserva los dos rasgos esenciales con los que ya había nacido en la inmediata posguerra: servicio público e independencia frente al poder político» ${ }^{62}$.

En Alemania, el ordenamiento jurídico vigente aplicable a los medios de comunicación incluirá tanto a la radio como a la televisión, siendo sus principios,

54 Salvador Martínez, M., «El modelo audiovisual...», op. cit., p. 366. Sobre el papel de la radiotelevisión de la reunificación alemana, vid. Krotz, K., «De-The Radio...», op. cit., p. 124.

55 Así lo confirmó la «tercera» BVerfGE 57, 295, de 16 de junio de 1981. Esta sentencia junto con la «cuarta» contribuyeron a consolidar el sistema dual de la televisión alemana. Crítico con la introducción y consolidación del sistema dual, vid. Bomas, W., «Der duale Rundfunk. Seine Bedeutung für die Entwicklung des Rundfunkmarktes», en Arbeitspapiere des Instituts für Rundfunkökonomie an der Universität zu Köln, Heft 206, 2005 (p. 46).

56 Sobre esta cuestión, vid. García-Muñoz, N./LARrÉgola, G., «La TDT en Europa. Modelos de programación», en Telos, n. ${ }^{\circ}$ 84, 2010, pp. 65-66 y 68-69 (pp. 65-72), quienes señalan que el modelo alemán es un claro ejemplo de que los canales TDT de cobertura estatal se crearon entre el 2003-2005, pues en Alemania, entre 2003-2004 surgieron el 73\% de canales generalistas y temáticos; y, también, BustamANTE, E. «Hacia un nuevo sistema televisivo: errores y frenos en el camino digital», en Telos, n. ${ }^{\circ}$ 53, 2002.

57 González EnCinar, J.J., «Modelos comparados...», op. cit., p. 102.

58 QuAdra-SAlCEdo, T. DE LA, «Informe preliminar...», op. cit., p. 35.

59 Este modelo no es sólo a nivel federal, sino que los Länder también han adoptado este mismo sistema dual. Al respecto, vid. Salvador Martínez, M., «El modelo audiovisual...», op. cit., p. 366.

60 BVerfGE 12, 205 (261).

61 BVerfGE 57, 295 (325). En relación con el tipo de programación, vid. KRoTz, K., «De-The Radio...», op. cit., pp. 129-130.

62 GonZÁlez EnCinar, J.J., «Modelos comparados...», op. cit., pp. 100-101. 
estructura y organización los mismos, con las salvedades que el medio de transmisión conlleva. Los principios que rigen el régimen jurídico de la radiotelevisión alemana son: principalmente, la independencia y neutralidad política, la estructura descentralizada, la atribución de competencias sobre esta materia a los Estados (Länder) y la vinculación a la sociedad mediante un sistema de pluralismo interno ${ }^{63}$. Estos principios, junto con otra serie de disposiciones generales, así como la regulación jurídica de las televisiones públicas y privadas se recogerá en el ya citado Acuerdo Federal sobre Radiotelevisión y Telemedia (Staatsvertrag für Rundfunk und Telemedien - Rundfunkstaatsvertrag, RStV). El RStV es un Acuerdo entre los dieciséis Länder que componen Alemania con la finalidad de unificar criterios en materia audiovisual. El $R S t V$ vigente es el de 31 de agosto de 1991, en su Decimoquinta modificación, de 15 al 21 de diciembre de 2010, en vigor desde el 1 de enero de $2013^{64}$.

Junto a este Acuerdo, para el sector público tendremos que tener en cuenta, además, los Acuerdos celebrados con las principales cadenas públicas, la $A R D$ (Arbeitsgemeinschaft der öffentlich-recbtlichen Rundfunkanstalten der Bundesrepublik Deutschland) y la ZDF (Zweite Deutsche Fernsehen) ${ }^{65}$. Y, para el sector privado, debemos tener en cuenta las Leyes o Acuerdos de creación de las Instituciones de los Medios. Asimismo, deberemos observar los Acuerdos relacionados con la contribución a la radiotelevisión (Rundfunkbeitragsstaatsvertrag, $R B S t V$ ) y el relativo a la financiación de la radiotelevisión (Rundfunkfinanzierungsstaatsvertrag, RfinStV $)^{66}$. Y sobre las normas de control, además de lo establecido por los respectivos Acuerdos o Leyes de creación de las Instituciones de Radiotelevisión (sector público) o

63 Conforme a la «séptima» BVerfGE 87, 181, de 6 de octubre de 1992, para garantizar la libertad de los medios de comunicación también se hacía evidentemente necesario un sistema de financiación. Así, el $B V \operatorname{erf} G$ exige la existencia de una organización, una financiación, y un funcionamiento interno que cumplan con los requisitos constitucionalmente establecidos.

64 No obstante, existe una Decimosexta modificación de 1 de abril de 2015; y un proyecto de una Decimoctava modificación, de 15 de mayo de 2015, con modificaciones sobre la protección de la juventud (en concreto del Jugendmedienschutz-Staatsvertrag, JMStV)). Al respecto, vid. DreYer, S./WolfGANG, S., «Achtzehnter Staatsvertrag zur Änderung rundfunkrechtlicher Staatsverträge», en Paper del Hans-Bredow-Institut, Hamburgo, de 8 de julio de 2015. La referencia a los servicios telemedia (de información y comunicación electrónicos) se produjo a partir del año 2007. No obstante, dichos medios tienen su regulación específica (Ley de servicios telemedia (Telemediengeset, TMG), de 26 de febrero de 2007, modificada por última vez el 1 de abril de 2015); y $\$ \S 54$ a $61 R S t V$. Asimismo, el $R S t V$, desde el año 2003 dejó de hacer referencia a la protección de la juventud en los medios de comunicación, cuestión recogida desde ese momento en una norma creada a tal efecto. Sobre la protección de la infancia y la juventud, vid. Ley de protección de la juventud (Jugendschutzgesetz, JuSchG), de 23 de julio de 2002, modificada por última vez el 7 de agosto de 2013.

65 Vid. ARD-Staatsvertrag, firmado por los Länder el 27 de marzo de 1953; Y ZDF-Staatsvertrag, de 31 de agosto de 1991 (en la redacción dada por la Duodécima versión del Acuerdo Federal de Radiotelevisión y Telemedia, que entró en vigro el 1 de junio de 2009).

66 Vid. Rundfunkbeitragsstaatsvertrag (RBStV), de 15 de diciembre de 2010, tras la redacción dada por la Decimoquinta versión del Acuerdo federal sobre Radiotelevisión y Telemedia (RStV), entrada en vigor el 1 de enero de 2013. Y también, Rundfunkfinanzierungsstaatsvertrag (RfinStV), de 26 de agosto a 11 de septiembre de 1996. Modificado por última vez por la Decimosexta versión del Acuerdo federal sobre Radiotelevisión y Telemedia (RStV), del 4 al 17 de julio de 2014, entrada en vigor el 1 de abril de 2015 (y el 1 de enero de 2017). 
de las Instituciones de los Medios (sector privado), habrá que tener en cuenta las normas que regulan los Comités y Comisiones creadas para controlar aspectos concretos de los medios públicos y privados, como, por ejemplo, la Comisión para determinar las necesidades financieras (Kommission zur Ermittlung des Finanzbedarfs, $K E F$ ), la Comisión para el seguimiento de la concentración de medios (Kommission für die Ermittlung der Medienkonzentration, KEK), la Comisión de Licencias y Supervisión (Kommission für Zulassung und Aufsicht, ZAK) o la Comisión para la protección de la juventud en los medios (Die Kommission für Jugendmedienschutz, KJM).

En el mercado radiotelevisivo, la polémica se ha generado por la posibilidad de emitir los programas y contenidos a través de Internet. Los principales opositores de esta nueva forma de emisión fueron los editores de prensa escrita, como era de esperar (recordamos aquí la Declaración de Munich ya citada). Pero en este punto el Acuerdo Federal de Radiotelevisión, $R S t V$, limitó la emisión a la condición de que los contenidos tuvieran una relación directa con la programación tradicional y limitó su regulación a los servicios telemedia ${ }^{67}$; y, el $B V \operatorname{erf} G$ se pronunció señalando que con la emisión en Internet se garantizaba que la clásica forma de emisión del servicio público de radiotelevisión tuviera continuidad en el tiempo y se adaptara a los nuevos medios. No obstante, con el fin de garantizar el cumplimiento del servicio esencial de los medios de comunicación, y confirmar que un determinado servicio telemedia cumple con dicha función ${ }^{68}$, y que no sólo busca copar el mercado, en el año 2009, con la Duodécima revisión del $R S t V$, se introdujo el llamado Test de los Tres Niveles (Drei Stufen Test).

Por último, debemos señalar aquí, que lo que caracteriza al sistema alemán, en relación con los diferentes modelos de sistema dual que existen en Europa es que en él se ha establecido con claridad qué función cumple cada una de estas dos modalidades de televisión y cuál debe ser, de acuerdo con ello, el régimen jurídico de una y de otra. Así, algo realmente peculiar y característico del modelo alemán es que, al contrario de lo que ocurre en la mayoría de los países del resto de Europa (a excepción del Reino Unido), las cadenas públicas no luchan por su supremacía frente a las privadas, sino que las cadenas públicas gozan de una confianza superior a la de las privadas en temas informativos, llegando a liderar el mercado en este terreno ${ }^{69}$. El modelo alemán de televisión pública «es uno de los que mejor representa la posibilidad de crear un producto periodístico de calidad y, al mismo tiempo, popular» ${ }^{70}$.

\section{$67 \S 11 \mathrm{~d} R S t V$.}

$68 \S 11 \mathrm{f} .4 R S t V$.

69 Al respecto, vid. CAMÁÑEZ, G.C., «Televisión en Europa: análisis y comparativa de la principales cadenas públicas en seis países», en Revista Comunicar, n. ${ }^{\circ} 25,2005$, pp. 337-338 y 341-342 (pp. 336-342).

70 BAELo, P., «Alemania. Independencia en la televisión pública y regulación en la privada», en Cuadernos de Periodistas, 2011, pp. 44-48 (pp. 44-45), quien los define como «creadores de opinión», aportando los datos de que hasta un $69 \%$ de los telespectadores alemanes se decantan por la televisión pública para informarse en periodos electorales frente al $44 \%$ de la prensa escrita, el 23\% de la radio y el 18\% en Internet. 


\section{La radiotelevisión pública: las Instituciones de Radiotelevisión (Rundfunkrechtsanstalten)}

La radiotelevisión pública se ofrece en Alemania a través de las denominadas Instituciones de Radiotelevisión (Rundfunkrechtsanstalten, o también, öffentlich-rechtlicher Rundfunkanstalten). Las Instituciones de Radiotelevisión son instituciones de derecho público, con personalidad jurídica propia y plena capacidad de obrar. Están dotadas de lo que el $B V \operatorname{erf} G$ ha denominado «autonomía funcional», esto es, una autonomía cualificada de la que disfrutan sólo ciertas Administraciones independientes, caracterizadas porque no cumplen una función propiamente estatal, sino un servicio público: en este caso, la garantía de los derechos y libetades de la comunicación y la formación de la opinión pública libre. Se busca asegurar que el Estado no intervenga en la gestión de la radiotelevisión. Pero con el fin de que el modelo tampoco quede sujeto sólo a las reglas del libre mercado, se crean estas Instituciones para garantizar la existencia de una televisión ahora y en el futuro ${ }^{71}$.

Asimismo, la creación de las citadas Instituciones obedece al mandato constitucional (con reserva de ley) de garantizar la libertad de información de los medios de comunicación, el pluralismo y la libre formación de una opinión pública (art. $5 G G$ ). Así, las mismas se crean por Ley o bien por el Acuerdo Federal de Radiotelevisión entre los Länder, que tiene rango de ley ${ }^{72}$.

Las radiotelevisiones públicas se encuentran reguladas en los $\$ \S 11$ a 19 a del citado $R S t V$, que también recoge la obligación de mantener el equilibrio, la imparcialidad, la objetividad y la debida diligencia periodística con el fin de servir a la función de servicio público ${ }^{73}$.

A nivel nacional, emitiendo para todo el país, existen dos canales de televisión pública: el emitido por parte de la ARD (el Primer canal o Erstes Deutsches Fernsehen); y el emitido por la ZDF (el Segundo canal o Zweites Deutsches Fernseben). La ARD es una Asociación que reúne a todas las televisiones públicas de todos los Länder, mientras que la ZDF es una Institución creada por un Acuerdo estatal entre todos los Länder.

Una muestra de la compleja estructura descentralizada, se plasma en la creación en 1950 de la citada ARD, la Asociación de trabajo de las Instituciones de Radiotelevisión de la República Federal Alemana (Arbeitsgemeinschaft der öffentlich-rechtlichen Rundfunkanstalten der Bundesrespublik Deutschland). La ARD es la manifestación más importante de cooperación entre Instituciones de Radiotelevisión: se creó para la defensa de los intereses comunes a todas las Instituciones de Radiotelevisión en el ejercicio de sus funciones y para mejorar la colaboración en

71 Vid. BVerfGE 31, 314 (321); 59, 231 (254-255).

72 A juicio del $B \operatorname{Verf} G$ sólo con la reserva de ley se puede garantizar el cumplimiento de los principios constitucionales. Estos Acuerdos deben ser ratificados posteriormente por los Parlamentos de cada Land para entrar en vigor, adquiriendo así el rango de ley necesario (BVerfGE 12, 205 (261-263); y 57, 295 (319 y ss.)).

$73 \S 11 R S t V$. 
cuestiones técnicas, jurídicas, económicas o de cualquier otro tipo que les pudieran afectar. Pero, sin duda, la principal actividad de la ARD es la emisión del denominado «Primer canal» (Das Erste), emitido para todo el territorio nacional y que, en realidad, es un canal creado por programas elaborados, a su vez, por cada uno de los Länder que forman parte de la Asociación. La ARD se creó a través del Fernsehensvertrag firmado por todas las Instituciones de la ARD el 27 de marzo de 1953. Este contrato es un acuerdo administrativo entre las citadas Instituciones donde se acuerdan tanto objetivos y funciones como organización y forma de cooperación a través del citado Primer canal $^{74}$. Asimismo, la regulación de la ARD se detalla en el ARD-Staatsvertrag, de 31 de agosto de $1991^{75}$, y en sus Estatutos (ARD-Satzungen), y Directrices de actuación (Leitlinien) ${ }^{76}$.

Por su parte, la ZDF fue creada por un Acuerdo estatal, de 6 de junio de 1961, el Staatsvertrag uber die Errichtung der Anstalt des öffentlichen Rechts, Zweites Deutsches Fernsehen (ZDF-StV). Asimismo, su regulación se detalla en sus Estatutos (ZDF-Satzungen $)^{77}$, siendo realmente destacable la aprobación de un Código de comportamiento destinado a prevenir la corrupción $(Z D F-\text { Mitarbeiterkodex })^{78}$.

Junto a estos dos canales, a nivel estatal, hoy en día existen en Alemania once Instituciones de Televisión, que emiten un canal de televisión en el ámbito territorial del Estado (Land o Länder) que las ha creado por Ley o mediante el correspondiente Acuerdo interestatal. En la actualidad estas once Instituciones son las nueve Instituciones que, además, forman parte de la $A R D$ (los llamados «Terceros canales» («Dritten Fernsehprogramme», más conocidos como «Die Dritten»)), con la Deutsche Welle y con Deutschlandradio ${ }^{79}$. «Los Terceros» o nueve Instituciones que contro-

74 En la actualidad, versión de 26 y 27 de septiembre de 1991, modificado por última vez el 12 de septiembre de 2006. El grado de cooperación, que se fija también mediante Acuerdo («Fernsebvertragsschlïs$s e l »)$ se ha visto modificado por última vez por los Intendentes de la $A R D$ el 18 de septiembre de 2013 para el año 2015.

75 Con la redacción dada por la Decimosegunda revisión del $R S t V$, que entró en vigor el 1 de junio de 2009.

76 El Estatuto de la ARD (ARD-Satzung) se elaboró por las propias Instituciones los días 9 y 10 de junio de 1950, en la redacción de 8 de abril de 2014. Asimismo, las Directrices de actuación de la ARD (ARD-Leitlinien) para los años 2015/2016 (así como el Informe del resultado de los años 2013/2014) tienen una vigencia de 2 años — tal y como se dispuso en la Séptima redacción del $R S t V(\$ 11)$, de 23 al 26 de septiembre de 2003, y con efectos desde el 1 de abril de 2004, al exigir a la $A R D$, a la $Z D F$ y a Deutschlandradio la presentación de unos Estatutos y unas Directrices a partir de octubre de 2004-.

77 El Estatuto se aprobó el 2 de abril de 1962, modificado por última vez el 13 de marzo de 2015. El compromiso informativo de la ZDF durante el plazo de 2 años se recoge en sus Leitlinien para el 2015/2016. Asimismo, la ZDF tiene Directrices en relación con la programación (de 2 de abril de 1962, modificadas el 11 de diciembre de 2009), con la publicidad y el sponsoring (de 2 de abril de 1962, modificada el 12 de marzo de 2010), con la defensa de la juventud (de 22 de septiembre de 2000, modificada el 10 de octubre de 2013), y en relación con la autorización para los servicios multimedia (de 26 de junio de 2009).

78 Sobre dicho Código, aprobado el 5 de agosto de 2010, vid. http://www.zdf.de/ZDF/zdfportal/ blob/26890782/1/data.pdf (Consultado: 6/08/2015).

79 El número de estas Instituciones ha ido variando a lo largo de los años, en función de las diferentes fusiones y escisiones que se han producido en el seno de las mismas. Tenemos que señalar aquí que junto a las Leyes o Acuerdos de creación de dichas Instituciones, las mismas se rigen por sus propios Estatutos (Satzungen). 
lan los programas regionales que integran la $A R D$ son: la Bayerischer Rundfunk (BR) para el Land de Bayern ${ }^{80}$, la Hessischer Rundfunk (br) para el Land de Hesse ${ }^{81}$, la Mitteldeutscher Rundfunk (MDR) para los Länder de Sachsen-Anhalt, Sachsen y Thüringen ${ }^{82}$, la Norddeutscher Rundfunk (NDR) para los Länder de Hamburgo, Mecklenburg-Vorpommern, Niedersachsen y Schleswig-Holstein ${ }^{83}$, la Radio Bremen $(R B)$ para el Land de Bremen y para la región metropolitana de Oldenburg ${ }^{84}$, la Rundfunk Berlin-Brandenburg (rbb) para los Länder de Berlin y Brandemburgo ${ }^{85}$, la Saarländischer Rundfunk (SR) para Saarland ${ }^{86}$, la Südwestrundfunk (SWR) para los Länder de Baden-Württemberg y Rheinland-Pfalz ${ }^{87}$, y la Westdeutscher Rundfunk Köln (WDR) para el Land de Nordrhein-Westfalen ${ }^{88}$. Die Dritten, además de contribuir a la elaboración de la programación del Primer canal (Das Erste), tienen en la

80 Vid. http://www.br.de/index.html; y Ley de creación y funciones de la Institución de Derecho público Bayerischer Rundfunk (BR) (Gesetz uber die Errichtung und die Aufgaben einer Anstalt des öffentlichen Rechts — "Der Bayerische Rundfunk», BayR-G), en la redacción de 22 de octubre de 2003, modificada última vez el 27 de noviembre de 2012. Tiene como antecedente más conocido la que fue la primera concesión de radiotelevisión alemana, la Deutsche Stunde in Bayern, creada en 1922 y concedida en 1923, convertida en Institución de Radiotelevisión en enero de 1949 y pasando a ser la primera Institución de la ARD en septiembre de 1964.

81 Vid. http://hessenschau.de/index.html; y Ley sobre la Radiotelevisión de Hesse (Gesetz über den Hessischen Rundfunk, HR-G), de 2 de octubre de 1948, modificada última vez el 24 de junio de 2010. Comenzó a emitir su Tercer Canal de Televisión en octubre de 1964.

82 Vid. http://www.mdr.de/index.html; y Acuerdo estatal sobre la Mitteldeutscher Rundfunk (Staatsvertrag über den Mitteldeutschen Rundfunk, MDR-StV), firmado entre los Länder de Sachsen, Sachsen-Anhalt y Thüringen, el 30 de mayo de 1991.

83 Vid. http://www.ndr.de/; y Acuerdo estatal sobre la Norddeutscher Rundfunk (Staatsvertrag über den Norddeutschen Rundfunk, NRD-StV), firmado entre los Länder de Hamburg, Niedersachsen, Schleswig-Holstein (todos desde 1956), y Mecklenburg-Vorponmmern (desde 1992), el 17 y 18 de diciembre de 1991, modificado última vez el 1 y 2 de mayo de 2005 (entró en vigor el 1 de agosto de 2005). Surgió como consecuencia de la división entre 1954 y 1956 de la Nordwestdeutscher Rundfunk (NWRD) en esta NDR y en la Westdeutscher Rundfunk Köln (WDR). 2014.

84 Vid. http://www.radiobremen.de/; y Ley de Radio Bremen (Radio Bremen Gesetz, RB-G), 4 de abril de

85 Vid. http://www.rbb-online.de/; y Acuerdo estatal sobre la creación de una Institución de Radiotelevisión conjunta de los Länder de Berlin y Brandemburgo (Staatsvertrag über die Errichtung einer gemeinsamen Rundfunkanstalt der Länder Berlin und Brandenburg, rbb-StV), de 25 de junio de 2002, modificado por última vez el 30 de agosto/11 de septiembre de 2013. Aquí también debemos tener en cuenta el Acuerdo estatal sobre el trabajo conjunto entre Berlín y Brandemburgo en el terreno de los Medios de comunicación (Staatsvertrag über die Zusammenarbeit zwischen Berlin und Brandenburg im Bereich der Medien, MStV), de 29 de febrero de 1992, modificado por última vez el 30 de agosto/11 de septiembre de 2013 (entrada en vigor el 1 de enero de 2014). Esta Institución surge como consecuencia de la fusión de las Instituciones de Radiotelevisión Ostdeutsche Rundfunk Brandenburg (ORD) y la Sender Freies Berlin (SFB) el 1 de mayo de 2003.

86 Vid. http://www.sr-online.de/sronline/index.html; y Ley de Medios de Saarland (Saarländisches Mediengesetz, Saar-G), de 27 de febrero de 2002, modificada por última vez el 25 de abril de 2007.

87 Vid. http://www.swr.de/; y Acuerdo estatal sobre la Südwestrundfunk (Staatsvertrag über den Südwestrundfunk, SWR-StV), de 3 de julio de 2013 (entrada en vigor el 1 de enero de 2014). Surge como consecuencia de la fusión de las Instituciones de Radiotelevisión Süddeutscher Rundfunk (SDR) y la Südwestfunk (SWF) el 1 de octubre de 1998.

88 Vid. http://www1.wdr.de/themen/index.html; y Ley sobre la Westdeutscher Rundfunk Köln (Gesetz über den Westdeutschen Rundfunk Köln, WDR-G), de 23 de marzo de 1985, modificada por última vez el 5 de julio de 2011. Surgió como consecuencia de la división entre 1954 y 1956 de la Nordwestdeutscher Rundfunk (NWRD) en la ya citada Norddeutscher Rundfunk (NDR) y en esta WDR. 
actualidad su propia programación con un alto contenido, como es lógico, de información regional, y de programas de contenido educativo y cultural.

Por último, la Federación, en ejercicio de la competencia reconocida por el $B V \operatorname{erf} G$ ha creado una televisión para emitir sólo a nivel internacional, al extranjero, la Deutsche Welle $(D W)$, que será otra de las Instituciones de Radiotelevisión ${ }^{89}$. Finalmente, como undécima Institución de Radiotelevisión, más bien de Radio, encontraremos Deutschlandradio ${ }^{90}$.

Por otro lado, en colaboración con televisiones extranjeras, las televisiones públicas emiten también otros canales: el canal de cultura «Arte» (la $A R D$ y la $Z D F$ en colaboración con el socio francés ARTE France); y el programa cultural de habla alemana «3sat» (coorganizado por la $A R D$ y la $Z D F$, en colaboración con el socio austriaco ORF y con el socio suizo SRG SSR idée suisse $)^{91}$.

Dentro de la programación pública, como canales temáticos emitidos por la colaboración entre la $A R D$ y la $Z D F$, nos encontramos con el canal infantil KI.KA y con el canal de documentales PHOENIX ${ }^{92}$. Asimismo, debemos mencionar la oferta pública digital: ARD digital y ZDFvisión, con programas como EinsFestival o ZDFinfokanal ${ }^{3}$.

Por último, por lo que se refiere al paisaje radiofónico, el mismo ha cambiado considerablemente. En la actualidad un total de unos sesenta programas de radio públicas se enfrentan a más doscientos programas privados ${ }^{94}$. La cadena

89 También se había creado la Deutschlandfunk $(D L F)$ aunque la misma dejó de emitir a principios de 1994. Ambas instituciones creadas por la Ley de creación de las Instituciones de Radiotelevisión de la Federación, Gesetz uber die Errichtung von Rundfunkanstalten des Bundesrechts (BR-G), de 29 de noviembre de 1960. Sobre la $D W$, vid. http:/www.dw.com/de/unternehmen/profil/s-30626; y la Ley sobre la Institución de Radiotelevisión de la Federación «Deutsche Welle» (Gesetz über die Rundfunkanstalt des Bundesrechts «Deutsche Welle» — Deutsche-Welle-Gesetz — DWG), de 16 de diciembre de 1997, modificada por última vez el 15 de diciembre de 2004. Y sobre sus objetivos (http://www.dw.com/popups/pdf/34622026/das-leitbild-der-deutschen-welle-zum-weiterreichen.pdf (Consultado: 6/08/2015); y su planificación, aprobada por el Consejo y el Consejo de Administración el 27 de febrero de 2015, vid. el Aufgabenplanung Deutsche Welle 2014-2017 (http://www.dw.com/popups/pdf/44249105/aufgabenplanung.pdf. Consultado: 6/08/2015).

90 Vid. http://www.deutschlandradio.de/; y Acuerdo estatal sobre Deutschlandradio (Deutschlandradio-Staatsvertrag), de 17 de junio de 1993, en la redacción dada por la Decimoquinta versión del Acuerdo Federal sobre Radiotelevisión y Telemedia $(R S t V)$, que entró en vigor el 1 de enero de 2013. Deutschlandradio cuenta con un Código de principios periodísticos (Journalistisches Selbstverständnis), aprobado en agosto de 2015 (http://www.deutschlandradio.de/index.media.6d1324ff114ae9edff85a35f2a3e0cde.pdf. Consultado: 6/08/2015), así como con unos Principios de actuación periodística (Verbaltensgrundsätze), aprobados el 27 de enero de 2015 (http://www.deutschlandradio.de/index.media.44f9d2a0fb652af78b71e960baa0750b.pdf. Consultado: 6/08/2015), y sus propios Estatutos (Satzung der Körperschaft des öffentlichen Rechts „Deutschlandradio«), aprobados por el Consejo de Administración el 26 de mayo de 1994, modificado por última vez el 18 de junio de 2014 (http://www.deutschlandradio.de/index.media.4894cdb84d1d17c91eed6c584c3a8b1c. pdf. Consultado: 6/08/2015). Por último, señalamos que Deutschlandradio cuenta con tres Programas de radio: Deutschlandradio Kultur, Deutschlandfunk y DRadio Wissen (vid. § 11c.(3) RStV).

$91 \S 11 \mathrm{~b} .(4) R S t \mathrm{~V}$.

$92 \S 11 \mathrm{~b} .(4) \mathrm{RStV}$.

$93 \S 11 \mathrm{~b} .(1) .2$ y (3). 2 RSt $\mathrm{V}$.

94 Fenske, U./Trkulja, V., «VI. Medien in Deutschland», en Zeit für die Schüle, 2005/2006, 2006, p. 78; y Hoffmann-Riem, W., Regulierung der dualen Rundfunkordnung. Grundfragen, Nomos-Verlagsgesell- 
pública ARD controla entre cinco y seis programas del total de las emisoras regionales, y dos emisoras de radio a nivel nacional. Por otro lado, en el sector privado, hay más de cuarenta emisoras regionales, y casi ciento cincuenta programas locales y regionales. Pero en el sector radiofónico van a primar los programas locales con ofertas en noticias, información o programas de entretenimiento ${ }^{95}$. Hoy en día en las emisoras públicas y privadas dominan las llamadas «radios de formato», que están marcadas por un determinado estilo musical y por la continua dependencia de las cuotas de mercado ${ }^{96}$. Asimismo, debemos señalar para concluir que la radio se encuentra, como la televisión, inmersa en un proceso de digitalización, y que desde el 2011 se están ofreciendo programas de radio nacionales a través de onda digital terrestre y se están explorando nuevos medios como la radio a través de Internet. Todo ello con el correspondiente control para evitar la concentración de medios y la lesión del pluralismo ${ }^{97}$.

\section{A) Organización interna}

Dado que las Instituciones de Radiotelevisión se han creado todas por Ley o por los citados Acuerdos interestatales, las diferencias entre ellas serán mínimas, al ser muy claras y precisas, siendo su organización prácticamente idéntica en todas. Así, en relación con su estructura interna en Alemania se exige que la misma sea democrática, esto es, que los órganos creados se compongan exclusivamente de representantes de todos los sectores sociales, porque conforme al principio de igualdad todos ellos tienen el mismo derecho a participar en las decisiones que se adopten ${ }^{98}$. Estas Instituciones se componen, esencialmente, de tres órganos: el Consejo de Radiotelevisión (Rundfunkrat), el Consejo de Administración (Verwaltungsrat), y el Intendente (Intendent).

a) El Consejo de Radiotelevisión (Rundfunkrat)

Ya se denomine Rundfunkrat, Fernsehrat como en la ZDF o Hörfunkrat como en la Deutschlandradio, este Consejo es el máximo representante de la Institución,

schaft, Baden-Baden, 2000, p. 24 y ss. Al respecto, vid. el Informe anual de la Institución de las Radiotelevisiones privadas, la Medienanstalten (LMA) para el 2014/2015: Die medienanstalten — Jabrbuch 2014/2015, enero de 2014, p. 112.

95 Fenske, U./Trkulja, V., «VI. Medien in...», op. cit., p. 78.

96 Goldhammer, K., «Entwicklung des privaten Rundfunks», en Informationen zur politischen Bildung, n. $309 / 2010$, p. 34 (pp. 30-36).

97 Informe anual de la Institución de las Radiotelevisiones privadas, la Medienanstalten (LMA): Die medienanstalten — Jabrbuch 2014/2015, enero de 2014, p. 112; y $\S 11 \mathrm{c}$ y $11 \mathrm{f} R S t V$, así como el $\S 20 \mathrm{~b} R S t V$ relativo a la radio en Internet por parte del sector privado.

$98 \S 11 .(1)$ y $11 \mathrm{e} R S t V$. 
el garante de la programación y el que, sólo o de forma conjunta con el Consejo de Administración, elige al Intendente o Director.

El número de miembros del Consejo puede ir desde los 26 de Radio Bremen, los 74 de $S W R$, hasta los 77 de la ZDF. Su composición es también muy variada pero, en todo caso, debe garantizar que todas las organizaciones, confesiones religiosas, grupos e instituciones del correspondiente Land están representados, así como que se cumpla con el principio de igualdad entre hombres y mujeres, reflejando el pluralismo existente en la sociedad para, de ese modo, asegurar la prestación del servicio esencial de radiotelevisión y la libertad en el proceso de formación de la opinión pública9 ${ }^{99}$. La duración del mandato también variará de 4, 5 a 6 años. Y su Presidente es elegido entre todos ellos ${ }^{100}$.

Para garantizar la independencia de sus miembros en el ejercicio de sus funciones la Leyes o Acuerdos de creación establecen, por un lado, una serie de incompatibilidades como, por ejemplo, la incompatibilidad de pertenecer a este Consejo y ser un trabajador de la propia Institución ${ }^{101} ;$ y, por otro lado, en relación con el mandato establecen como causa de cese, entre otras, la pérdida de la capacidad jurídica, o el haber sido expulsado del grupo o asociación a la que representa $^{102}$. La elección de los Consejeros también se ha configurado con el fin de asegurar la independencia de la Institución, limitando la participación de los representantes de los órganos estatales y de los representantes de los partidos políticos $^{103}$. Con el fin de reforzar dicha independencia, recordamos aquí que el $B V \operatorname{erf} G$, en el 2014, exigió una mayor independencia a la hora de nombrar a los miembros del Gobierno en este órgano (el caso concreto hacía referencia al Fernsehrat de la ZDF), haciendo especial alusión a los partidos políticos. El BVerfG concluyó que los representantes de los partidos políticos en el Consejo de Radiotelevisión deberían verse reducidos a un máximo de un tercio ${ }^{104}$.

Por último, en cuanto a sus funciones o competencias, entre otras cosas, participa en la elección de los miembros del Consejo de Administración; tiene atribuida potestad normativa para elaborar tanto sus Estatutos internos (Satzungen), como las Directrices de la programación; asimismo, resuelve las reclamaciones que se presenten; y aprueba el presupuesto anual y las cuentas anuales de la Ins-

99 Por ejemplo, art. 6 BayR-G; ó § $5 H R-G$. Sobre la participación de, al menos, una mujer, § 21.(4) $R S t V$.

100 En este sentido, BVerfGE 12, 205 (261); 83, 238 (332). Y, por ejemplo, § 19 NDR-StV.

101 Por ejemplo, art. 6.4 BayR-G.

102 Por ejemplo, § 21.(1) MDR-StV; y art. 6.(5) BayR-G.

103 Por citar alguna norma en la que se recoge la composición, vid. art. 6 BayR-G; y $\S 17$ NDR-StV.

104 El Tribunal Constitucional federal solicitó a los Länder que dicha reducción resultara efectiva a más tardar el 30 de junio de 2015. En el Consejo de Radiotelevisión de la ZDF la proporción de representantes de los partidos y del Estado se encuentra actualmente en más del $40 \%$ de los miembros. También en los órganos de control de las nueve cadenas públicas ARD, Deutsche Welle y Deutschlandradio se dan porcentajes similares. Criticando la participación de los partidos políticos con algún ejemplo, como los relacionados con Philip Röster y Anette Schawan, vid. Poptcheva, E.V., «Las autoridades independientes...», op. cit., pp. 295-296. 
titución, además de tener competencia en relación con las quejas presentadas por los telespectadores, con el fin de garantizar la calidad de la programación y el respeto de la legalidad en el terreno de la comunicación ${ }^{105}$. Sus deciones se toman normalmente por mayoría simple o cualificada, en función del tema; y podrán llegar a crear Comisiones en función de la materia ${ }^{106}$.

\section{b) El Consejo de Administración (Verwaltungsrat)}

Para todas las Instituciones de Radiotelevisión alemanas, el segundo órgano de control de las mismas lo representa el Verwaltungsrat. Este Consejo está formado entre 7 ó 9 miembros, que son elegidos por el Rundfunkrat ${ }^{107}$. Con el fin de asegurar el pluralismo, se llega a exigir que haya, al menos, una representación proporcional de representantes de los Länder, e incluso determinados porcentajes de representantes de un determinado Comité o Institución, o de empleados de la propia Institución ${ }^{108}$. El cargo de Consejero también está sujeto a una serie de incompatibilidades, siendo la regla general que no se pueda pertenecer al mismo y al Consejo de Radiotelevisión. En cuanto al mandato de los Consejeros, los mismos duran de 2 a 4 años, sin que sea posible la reelección, salvo que lo decida el Rundfunkrat por mayoría cualificada; por otro lado, algunas Instituciones prevén la renovación parcial de los Consejeros cada uno o dos años ${ }^{109}$.

El Verwaltungsrat actúa como órgano de apoyo del Consejo de Radiotelevisión y desempeña, sobre todo, funciones relacionadas con la dirección económica de la Institución (la aprobación de las cuentas y los presupuestos de la Institución), aunque también se encarga del control de la programación, así como de la propuesta de nombramiento del Intendente. Sus decisiones se toman por mayoría simple o cualificada.

\section{c) El Intendente (Intendant)}

Hoy en día el Intendente es el órgano ejecutivo de las Instituciones de Radiotelevisión. Por regal general, el Intendente ocupa una posición relevante, pero en algunas Instituciones su función es ejercida por alguno de los Directores de la emisora. En este sentido, el Director de Deutschlandradio también ocupa la posi-

105 Las funciones del Consejo se establecen, por ejemplo, en art. 7.(3) BayR-G; ó $§ 8 R B-G$. Sobre el procedimiento de quejas, vid., Poptcheva, E.V., «Las autoridades independientes...», op. cit., pp. $296-297$.

106 Sobre la creación de Comisiones, vid., por ejemplo en $\S 10 \mathrm{HR}-\mathrm{G}$; y $\S 24 \mathrm{MDR}-\mathrm{StV}$.

107 Incluso en la HR hasta mediados de 2004 lo componían sólo 6, o en el caso de la NDR lo integran hasta 12. Vid., por ejemplo, § $24 \mathrm{NDR}-\mathrm{StV}$; y $\S 25$ (1) MDR-StV.

108 Por ejemplo, en la MDR y en la NDR se exige un porcentaje de 1/4, o en la SWR, de 1/7.

109 Por ejemplo, § 12 HR-G; y $\$ 31$ SaarLR-G. 
ción de Intendente. La regla general será que el Intendente es elegido por el Rundfunkrat, a propuesta del Consejo de Administración, o como sucede en la Südwestrundfunk, es elegido entre ambos órganos, mediante acuerdo adoptado por mayoría simple ${ }^{110}$. Las Leyes o Acuerdos de creación de las Instituciones no exigen ningún requisito personal para ser Intendente, pero está sometido a la incompatibilidad de ser al mismo tiempo miembro de alguno de los Consejos de la Institución. El mandato del Intendente alcanza los 4, 5 ó 6 años, llegando incluso a los 9 de la Hessischen Rundfunk, con la posibilidad de ser reelegido, cesando al acabar su mandato o haber incumplido sus obligaciones ${ }^{111}$.

Su función consiste en representar y dirigir a la Institución, pero subordinado a los Consejos de Radiotelevisión y al de Administración ${ }^{112}$, necesitando la previa autorización de alguno de ellos para tomar cualquier decisión ${ }^{113}$. En este sentido, ambos Consejos realizan una función de control interno, correspondiendo el control externo al Tribunal de Cuentas o a los correspondientes Tribunales. El Intendente participa también en el nombramiento de alto cargos y es el encargado de la elección del personal de la Institución, siendo el único requisito que se le impone para su elección, que se refleje el pluralismo social existente ${ }^{114}$.

\section{d) Las Comisiones de la ARD}

Al margen de los órganos anteriormente citados, que se encuentran en cada una de las Instituciones de Radiotelevisión existentes, en la ARD, en tanto que la misma agrupa a nueve Instituciones de Radiotelevisión, existen además una serie de Comisiones creadas en el seno de la $A R D$ con el fin de coordinar la actividad de las diferentes Instituciones de Radiotelevisión que la integran. Estas Comisiones se encargan de controlar la correcta cooperación entre las Instituciones, así como con la $Z D F$ y con la Deutschlandradio en los programas que lleven a cabo de forma conjunta.

Entre estas Comisiones, además de las que se puedan crear para analizar asuntos concretos, existen unas que tienen carácter permanente (Ständige Fachkommissionen) y que se organizan por la temática de su trabajo: Comisiones sobre Derecho, Producción y Técnica, Financiación, Radio y sobre los «Terceros». Por regla general, la presidencia de estas Comisiones la ostentan los actuales Directo-

110 En Radio Bremen, a diferencia de lo que ocurre en el resto de Instituciones de Radiotelevisión, la función ejecutiva no recae en un órgano unipersonal, el Intendente, sino en un órgano colegiado el Direktorium, que se compone de dos a cuatro Directores elegidos por el Rundfunkrat cada 5 años ( $\$ 115$ y $16 R B-G$ ).

111 Por ejemplo, § 16.(1) HR-G; y § 34.(4) SaarLR-G.

112 Vid., por ejemplo, § 29.(4) NDR $-S t V$.

113 Por ejemplo, § 35.(4) SaarLR-G.

114 En radiotelevisión no existe la «libertad interna del medio» que existe en prensa (BVerfGE 59, 231 (258)) 
res encargados de dichas áreas. En esta línea, con el fin de coordinar los aspectos relacionados con la programación, se ha creado una Conferencia de Programas de Televisión (Fernsehprogrammkonferenz), cuyos miembros son los Intendentes o los Directores de programación de las Instituciones de Radiotelevisión, y cuyo Presidente es elegido por un periodo de, al menos, dos años, y será el Director de programación de Das Erste, el primer canal de televisión ${ }^{115}$.

Junto a estas Comisiones, existe la denominada «Comisión Histórica» («Historische Kommision») encargada de analizar la historia de la radiodifusión en Alemania y de sus efectos sociales. Esta Comisión, creada en 1954 cuenta con la participación de las Instituciones de la ARD, Deutschlandradio y la ZDF ${ }^{116}$.

En último lugar debemos destacar la Conferencia de Presidentes de los Consejos de las Instituciones que integran la ARD (Gremienvorsitzendenkonferenz, $G V K)^{117}$. Esta Conferencia es el órgano de control de la ARD. Entre sus funciones encontramos el asesoramiento sobre la programación, pero su función principal es coordinar y armonizar las actividades del resto de Comisiones de la ARD. Este Comité está integrado por el Presidente de la ARD y los Directores de las nueve Instituciones que componen la ARD y el de la Deutsche Welle. Por regla general la dirección la ostenta el Director del Rundfunkrat de una de las Instituciones ${ }^{118}$. Esta Conferencia tiene dos Subcomités, el Comité de Telemedia (Telemedienausschuss) y el Comité de Finanzas (Finanzasusschuss), compuesto por los miembros de los Consejos de Radiotelevisión y de los de Administración, respectivamente.

\section{B) Competencias y funciones}

Las Instituciones de Televisión disfrutan de potestad reglamentaria para regular su organización interna y su funcionamiento, lo que se refleja en sus Estatutos (Satzungen).

La función que deben cumplir las Instituciones de Televisión consiste en prestar el denominado «servicio esencial de televisión», lo que se refleja, fundamentalmente, en la elaboración y difusión de una determinada programación ${ }^{119}$. En este sentido, las Leyes de la Televisión de los Länder o Acuerdos interestatales no se limitan sólo a recordar dicha función, sino que, además, contienen una serie

115 Art. 2 ARD-Fernsehvertrag.

116 Su trabajo se desarrolla a través de los conocidos simposios: Simposio «Im öffentlichen Interesse — Bedeutung und Zukunft des öffentlich-rechtlichen Rundfunks», de 28 de mayo de 2014; y Simposio «Entstehung und Entwicklung des öffentlich-rechtlichen Rundfunks in den neuen Bundesländern», de 13 de septiembre de 2012.

117 § 7.2 ARD-Staatsvertrag; y $§ 5$ a.(1) ARD-Satzung.

118 Vid. \$ 19 NDR-StV.

119 Esencialmente, BVerfGE 74, 297 (326). 
de directrices que las Instituciones tienen que cumplir a la hora de emitir su programación: informar, formar y entretener ${ }^{120}$. Asimismo, en relación con la programacion, el $R S t V$ define unas reglas muy estrictas, siendo el criterio general el respeto a la dignidad humana, por lo que toda aquella programación que la violente, será prohibida ${ }^{121}$. Con esta finalidad se establecen también una serie de cuotas para ciertos programas y, asimismo, con estas directrices se regula la retransmisión de determinados programas como los comunicados del Gobierno, la publicidad electoral o la publicidad comercial ${ }^{122}$.

\section{C) La dirección económica y la financiación}

En relación con la dirección económica de estas Instituciones, a pesar de ser el Consejo de Radiotelevisión el que aprueba los presupuestos y las cuentas anuales, y el Consejo de Administración el encargado de la dirección económica de la Institución, es el Intendente el órgano ejecutivo y el encargado de ejecutar los presupuestos aprobados. Además del control interno que sobre el mismo recae por parte de ambos Consejos, de forma complementaria, en el nivel económico va a existir el control externo del Tribunal de Cuentas ${ }^{123}$.

Más allá de la dirección económica de la institución, hablar de la financiación de la radiotelevisión en Alemania supone admitir como punto de partida que el sistema debe ser dual, aunque el problema se va a producir porque habrá que tener en cuenta, también, la libre competencia del mercado ${ }^{124}$, así como las nuevas tecnologías que rompen con la escasez del espectro audiovisual y permiten nuevas y numerosas vías para distribuir los contenidos ${ }^{125}$.

Con el fin de que los poderes públicos no puedan utilizar el sistema de financiación para influir en la programación de las Instituciones de Radiotelevisión, el legislador alemán optó por establecer un sistema mixto de financiación: de una parte, ingresos procedentes de una contribución (hasta 2013, una tasa); y de otra, ingresos procedentes de la publicidad ${ }^{126}$.

120 § 11.(1) $R S t V ;$ y también, vid. \$§ 3, 11 y 11 e $R S t V$.

121 Vid. $\$ 3 R S t V ;$ y Acuerdo estatal para la defensa de la juventud en los medios de comunicación (Jugendmedienschutz-Staatsvertrag, JMStV), $\S \S 5$ a 8.

$122 \S \S 7$ a $10 R S t V$.

123 Vid., por ejemplo, art. 13.(3) y (4) BayR-G.

124 MuÑOZ MACHADO, S., «La financiación de la televisión pública y privada», en QuADRA-SALCEDO, T. DE LA, El régimen jurídico del audiovisual, Marcial Pons, Barcelona, 2000, pp. 184-185 (pp. 183-191).

125 Se ha llegado incluso a plantear que la publicidad deje de ser la principal fuente de financiación del régimen audiovisual. $\mathrm{Al}$ respecto, vid. DoyLE, G., «Economía audiovisual:...», op. cit., p. 17.

$126 \S 13 R S t V$. Vid., también, Fernández Lombao, T./Campos Freire, F., «La Responsabilidad Social Corporativa en las radio-televisiones públicas de Europa», en Cuadernos.info, n. ${ }^{\circ} 33,2013$, pp. 146, 149 y 154 (pp. 145-157). Al respecto, sobre el caso alemán, en el que el Gobierno federal publicó el 6 de octubre de 2010 la «Estrategia nacional de Responsabilidad Social Corporativa — Plan de Acción», vid. ZDF, Mit 
Sobre la financiación de los medios de comunicación el $B V \operatorname{erf} G$ se ha pronunciado hasta en tres ocasiones en sus conocidas «sentencias sobre la radiotelevisión». El Tribunal Constitucional federal ha mantenido que para las radiotelevisiones públicas, un sistema de financiación mixto es adecuado y que junto a la tasa pueden existir otras formas de financiación como la publicidad, el sponsoring o incluso la producción de programas y servicios propios. El $B V \operatorname{Verf} G$ ha entendido que la combinación de diversas fuentes de ingresos y el equilibrio entre ellas constituyen un elemento básico en la garantía de la independencia económica, pues supone una diversificación de las dependencias ${ }^{127}$. En esta línea el $B V \operatorname{verfG}$ ha reconocido que una garantía del mantenimiento y desarrollo de la televisión pública tiene como uno de sus elementos fundamentales la garantía financiera. Esto significa, por un lado, que el Estado debe garantizar que las Instituciones de televisión dispongan de los medios económicos necesarios para poder prestar el servicio esencial que tienen atribuidos ${ }^{128}, \mathrm{y}$, por otro lado, también significa que el legislador debe garantizar, al mismo tiempo, que estas Instituciones se mantengan independientes económicamente, tanto de los poderes públicos como de las reglas del mercado ${ }^{129}$, pues «un mercado no regulado no asignaría los recursos de un modo eficiente» ${ }^{130}$.

El sistema de financiación de la televisión pública se regula, en primer lugar, en el Acuerdo Federal sobre Radiotelevisión y Telemedia (Rundfunkstaatsvertrag, RS$t V)^{131}$; en segundo lugar en la Ley o Acuerdo de creación de la Institución de radiotelevisión de cada Estado; y, por último, en el Acuerdo sobre financiación de la radiotelevisión (Rundfunkfinanzierungstaatsvertrag, $R f i n S t V)^{132}$, así como en el Acuerdo sobre la contribución a la radiotelevisión (Rundfunkbeitragsstaatsvertrag, $R B S t V)^{133}$.

Los presupuestos destinados a las cadenas públicas rondan alrededor de los nueve millones de euros, siendo la $A R D$ la más beneficiada con el reparto, corres-

Perspektive für alle. Gesellschaftliches Engagement und unternebmerische Verantwortung des ZDF, 2011-2012, 2012 (Disponible en http://www.zdf.de/ZDF/zdfportal/blob/26292176/1/data.pdf. Consultado: 6/07/2015).

$127 \S \S 12$ y $13 R S t V ;$ y «sexta» BVerfGE 83, 238, de 5 de febrero de 1991.

128 BVerfGE 73, 118 (158), y $§ 12$ RfinStV. En este sentido, vid., también, «séptima» BVerfGE 87, 181, de 6 de octubre de 1992, donde el Tribunal dejaba claro la obligación de garantizar financieramente estas Instituciones para proteger la libertad de los medios de comunicación.

129 Sobre la ausencia de influencias estatales, vid. la «octava» BVerfGE 90, 60, de 22 de febrero de 1994, que dio paso a la creación de la KEF; y, por ejemplo, § 19.(1) RB-G, que excluye expresamente la financiación estatal.

130 Hargreaves Heap, S., «Television in a Digital Age: What role for public service broadcasting?», en Economic Policy, 20 (41), 2005, pp. 112-157. Y en el mismo sentido, vid. GraHAM, A., «Broadcasting Policy in the Multimedia Age «, en Graham, A. et al. (eds.), Public Purposes and Broadcasting: funding the $B B C$, University of Luton, Luton, 1999.

$131 \S \S 12$ a $14 R S t V$.

132 El Rundfunkfinanzierungstaatsvertrag, RfinStV, de 26 de agosto al 11 de septiembre de 1996, modificado por última vez por la Decimosexta revisión del Acuerdo Federal de Radiotelevisión y Telemedia, del 4 al 17 de julio de 2014, con entrada en vigor el 1 de abril de 2015 y en 1 de enero de 2017.

133 Rundfunkbeitragsstaatsvertrag, RBStV, de 15 de diciembre de 2010, en la redacción dada por la Decimoquinta revisión del Acuerdo Federal de Radiotelevisión y Telemedia, en vigor el 1 de enero de 2013. 
pondiéndole más de la mitad de los mismos ${ }^{134}$. Y, por lo que se refiere a la radio, ante las dificultades económicas provocadas por la limitación de la publicidad, por la crisis económica que comenzó en el 2008, y por el hecho de que las radios privadas se centraron en los oyentes más jóvenes con unos anuncios y programas atractivos para ellos, se provocó en el sector público un «rejuvenecimiento» de su programación, buscando nuevos productos con el fin de proteger el futuro de la radio pública ${ }^{135}$.

\section{a) La contribución por radiotelevisión (Rundfunkbeitrag)}

La principal fuente de financiación de los servicios públicos de radiodifusión es la actual contribución a la radiotelevisión (anterior tasa (Rundfunkgebübren)). Su cifra en 2015 alcanza los 17,50 euros mensuales por hogar ${ }^{136}$. Hasta hace poco, la contribución estaba diseñada como tarifa sobre el equipo, es decir, se pagaba por los aparatos de radio y/o televisión (desde 2007 también por los PCs habilitados para Internet y teléfonos móviles) ${ }^{137}$ que se tuvieran, independientemente de su utilización. Pero desde 2013 el sistema financiero sufrió un drástico cambio y pasó a convertirse en una cuota o contribución por hogar ${ }^{138}$, basándose en una

134 Vid. § 9.(1) RfinStV, que indica que el reparto presupuestario de la contribución por radiotelevisión será de un $72,0454 \%$ para la $A R D$, un $25,1813 \%$ para la $Z D F$ y un 2,7733\% para Deutschlandradio. Al respecto, vid. «Das ist die ARD. Zehn Rundfunkanstalten: Eine erfolgreiche Gemeinschaft». Disponible en https://web.archive.org/web/20131102035101/http://www.ard.de/intern/organisation/-/id=8036/rnvfb8/ index.html (Consultado: 6/07/2015).

$135 \mathrm{Al}$ respecto, vid. Handel, U. «Der Radiomarkt in Deutschland», en Fachjournalist, n. ${ }^{\circ}$ 2, 2002 , p. 16; y GOLDHAMmer, K., «Entwicklung des privaten...», op. cit., p. 34, quien señala que a partir del 2000, los ingresos publicitarios netos se redujeron cerca de un 9\%, unos 678 millones de euros entre 2007 y 2009.

136 Hasta el 31 de marzo de 2015 la tasa era de 17,98 euros mensuales. Al respecto, vid. § 8 RfinStV.

137 Sobre la obligatoriedad de la tasa respecto de ordenadores se pronunciaron afirmativamente tanto el Tribunal Federal Administrativo el 27 de octubre de 2010 (BVerwGE 6 C 12.09), como el Tribunal Constitucional Federal el 22 de agosto de 2012 (BVerfGE 1 BvR 199/11). Y sobre la polémica generada en la doctrina, vid. Göhmann, S./Schneider, A./Siekmann, K., «Kurzberichterstattung», en Hahn, W./VeSTING, TH., Beck'scher Kommentar zum Rundfunkrecht, 3. ${ }^{a}$, ed., Beck, Munich, 2012, pp. 207-236; y FIEBIG, A., Gerätebezogene Rundfunkgebührenpflicht und Medienkonvergenz, Duncker \& Humblot, Berlin, 2008

138 Sobre este cambio, entre otros, vid. Terschüren, A., Die Reform der Rundfunkfinanzierung in Deutschland, Universitätsverlag Ilmenau, Ilmenau, 2013. Este modelo, iniciado con la reforma de 2010, aprobada por los Gobiernos de todos los Länder y, posteriormente ratificada por sus Parlamentos en 2011 se basa en la Opinión legal de Paul Kirchhof (Gutachten über Die Finanzierung des öffentlich-rechtlichen Rundfunks erstattet im Auftrag der ARD, des ZDF und D Radio, Instituts für Finanz- und Steuerrecht Ruprecht-Karls-Universität Heidelberg, Heidelberg, abril 2010. Disponible en http://www.ard.de/download/398406/index.pdf. Consultado: 6/08/2015). Sobre la discusión doctrinal generada, vid., por todos, BosmaN, W., «Paradigmenwechsel in der Rundfunkfinanzierung», en KER, 2012, pp. 5-11; Ferreau, F./Рoth, H.C., «Der Rundfunkbeitragsstaatsvertrag», en $N v W Z, 2011$, pp. 714-717; MARTiN, K., «Rundfunkgebühren für alle: Das kommt auf Sie zu», en Merkur on line, de 15 de diciembre de 2012; y HaNFELD, M., "Neuer Rundfunkbeitrag: Ungleic behandelt», en FAZ Online, de 19 de diciembre de 2012. Y en la jurisprudencia, vid. Decisión del Tribunal Constitucional del Land de Bayern, de 15 de mayo de 2014 (Vf. 8-VII-12 y Vf. 24-VII-12); y Sentencia del Tribunal Constitucional del Land Rheinland-Pfalz, de 13 de mayo de 2014 (VGH B 35/12). 
sencilla regla: «un domicilio una contribución» ${ }^{139}$, sin tener en cuenta el número de personas que viven en la casa o el número de aparatos de radiotelevisión que se tienen $^{140}$.

La contribución de la radiotelevisión alemana se caracteriza porque la misma se ha diseñado de tal forma que no es un tributo estatal, sino que es una contribución directa de los ciudadanos, que es recaudada y distribuida por las propias Instituciones de Radiotelevisión, a través de un órgano creado a tal efecto: la «Comisión para el establecimiento de las necesidades financieras de la radiotelevisión» (Kommission zur Ermittlung des Finanzbedarfs der Rundfunkanstalten, $K E F)^{141}$. Esta Comisión se encarga de emitir un informe (cada dos años) sobre las necesidades financieras de las Instituciones de Radiotelevisión, que los Länder toman como referente para establecer la cuantía de la cuota. Los ingresos que se obtienen a través de su recaudación se reparten, en primer lugar, de acuerdo con una ratio prefijada entre la ARD, la ZDF y las Instituciones de los Medios de las televisiones privadas y, posteriormente, en el seno de la ARD, de acuerdo con el sistema de compensación entre las Instituciones de Radiotelevisión de cada Län$\operatorname{der}^{142}$. Las Comisiones correspondientes de las citadas Instituciones son las que se encargan de hacer el reparto ${ }^{143}$. La necesidad y la cuantía de la contribución por radiotelevisión han sido las cuestiones más dicutidas por la doctrina especializada en medios de comunicación y sobre la que, finalmente, se pronunció el $B V \operatorname{VerfG}$ confirmando la necesidad de asegurar mediante normas de procedimiento la libertad de los medios de comunicación frente a las influencias políticas que pudieran existir a la hora de fijar la cuantía de la tasa y su reparto ${ }^{144}$. Incluso la $K E F$,

139 Sobre el concepto de «domicilio», vid. § 3 Rundfunkbeitragsstaatsvertrag, RBStV.

140 Hallenberger, G., «Der öffentlich-rechtliche Rundfunk», en Informationen zur politischen Bildung, n. ${ }^{\circ} 309 / 2010$, pp. 26-29, con un claro ejemplo de los costes de creación de una Institución de Radiotelevisión, así como un claro debate con los pros y los contras de la tasa por titular de la vivienda. Cuestionándose el respeto al principio de igualdad de la citada contribución, vid., DegEnHART, CH., «Verfassungsrechtliche Zweifelsfragen des Rundfunkbeitragsstaatsvertrags», en ZUM, 2011, pp. 193-200; y, también, LENT, W., "Die neue Rundfunkbeitragspflicht für Wobnungsinhaber», en LKV, 2012, pp. 493-498. Y cuestionándose el respeto a la normativa de protección de datos: por un lado, HerB, A. «Datenschutzrechtliche Vorschriften im Rundfunkbeitragsstaatsvertrag», en $D u D$, 2011, pp. 270-274; y, por otro, Geuer, E., "Zur Verfassungswidrigkeit der «Haushaltsabgabe» für den öffentlich-rechtlichen Rundfunk», en Verwaltungsrundschau, 2012, pp. 378-381. Por último, apostando por una tasa por consumo de programación vid. informe del Consejo Asesor del Ministerio de Finanzas «Öffentlich-rechtliche Medien-Aufgabe und Finanzierung» 3/2014.

$141 \S 2$ RfinSt $V$, y sobre la misma, $\$ \S 1$ a 7 RfinStV.

$142 \S 11 R S t V$, desarrollado en los $\$ \S 12$ a 16 RfinStV. En Alemania existe un mecanismo de compensación financiera que funciona entre todas las Instituciones de Radiotelevisión y constituye una manifestación del principio de colaboración que rige en las relaciones entre los Länder. Actualmente se benefician de este mecanismos de compensación financiera, Saarländischen Rundfunk y Radio Bremen, con unos porcentajes que van del $53,76 \%$ al $46,24 \%$ ( $\$ 14$ RfinSt $V$ ).

$143 \S \S 1$, 3.(8), 5, 5a y 7 RfinSt V; y FernÁndez Lombao, T./CAmpos Freire, F., «La Responsabilidad Social...», op. cit., pp. 149-150, sobre la evaluación del valor público de la programación y su impacto en el mercado, con la realización del denominado «Test de Valor Público».

144 BVerfGE 90, 60. 
ante la propuesta de suprimir la publicidad de forma definitiva de las televisiones públicas, concluyó que renunciar completamente a la publicidad supondría elevar la tasa unos 1,25 euros por familia al mes ${ }^{145}$. La polémica se suscita porque esta tasa es la principal fuente de financiación de la radiotelevisión pública, representando su recaudación bastante más de la mitad de los ingresos totales de las Instituciones de Radiotelevisión.

b) La publicidad

La existencia de esta segunda fuente de ingresos, la publicidad, encuentra su justificación en que con su existencia se refuerza la independencia económica de la televisión pública frente al Estado, al no depender sólo de las ayudas que éste pueda brindar ${ }^{146}$. Pero, por otro lado, la televisión pública debe limitar su participación en el mercado publicitario para evitar caer en la tentación del reparto de la codiciada «tarta». De esta forma, se fomenta una programación de calidad y, por otro lado, se deja a las televisiones privadas más cantidad a repartir, permitiéndose que coexistan ambos modelos de televisión, bien porque no se disputan el mismo mercado, bien porque buscan objetivos diferentes ${ }^{147}$.

Los ingresos por publicidad constituyen, cuantitativa y cualitativamente, la segunda fuente de financiación de las Instituciones de Radiotelevisión, aunque la regulación de la emisión de publicidad es muy precisa. El legislador alemán ha regulado de forma estricta los tiempos de emisión y los contenidos de los espacios publicitarios: no se permiten espacios publicitarios en los denominados «Terceros canales» (aquéllos que emiten las Instituciones de Radiotelevisión para el ámbito territorial correspondiente), así como en los canales de emisión federal. Y, por otro lado, en los casos en los que la publicidad está permitida, se limita a 20 minutos semanales para la televisión y 90 minutos para la radio, pero también está prohibida a partir de las 20.00 horas, durante todo el domingo y durante los festivos ${ }^{148}$.

El porcentaje de dinero que las Instituciones de Radiotelevisión reciben por publicidad es una cantidad que es auditada anualmente por la $K E F$, quien, para

145 Vid. http://www.rundfunkbeitrag.de/ueber_uns/10_gruende_fuer_oeffentlich_rechtlichen_rundfunk/index_ger.html (Consultado: 7/06/2015).

146 Al respecto, vid. SAlvador Martínez, M., «El modelo audiovisual...», op. cit., p. 375.

147 Esta regulación obedece a la trasposición de la Directiva de Televisión sin fronteras; y, por otro lado, se desarrolla en las Directrices aprobadas por las propias Instituciones. Al respecto, vid. $\$ \S 7$ y 8 y 16 a $18 R S t V$. Así se estableció en la «séptima» BVerfGE 87, 181, de 6 de octubre de 1992. Vid. también, Gersdorf, H., Grundzüge des..., op. cit., pp. 161 y ss; y QuAdra-SAlCEdo, T. DE LA, «Informe preliminar...», op. cit., pp. 44-45, para quien la decisión pasa por fijar porcentaje de participación del 15\%, límites temporales de participación, o incluso (aunque con sus riesgos), una financiación exclusiva presupuestaria. Se ha llegado a plantear la renuncia a la publicidad en el sector público en tanto que la misma sólo representa un cinco por ciento de su presupuesto total. Al respecto vid. el informe del Consejo Asesor del Ministerio de Finanzas.

$148 \S 16 R S t V$. 
el año 2014 consideró que con la cifra asignada se aseguraba la independencia de las mismas ${ }^{149}$. No obstante, tenemos que señalar que la participación en los ingresos por publicidad por parte del sector público ha caído drásticamente en los últimos años, motivado porque las principales radiotelevisiones privadas, especialmente $S A T 1$ y $R T L$, ocupan con su publicidad el espacio de tiempo que las públicas tienen prohibido y que es cuando mayores cuotas de audiencia existen, esto es, a partir de las 20.00 horas y en los eventos deportivos. En la práctica, las radiotelevisiones públicas para evitar la citada prohibición y conseguir ingresos no emiten publicidad, pero contratan el patrocinio para los eventos deportivos.

\section{La radiotelevisión privada: las Instituciones de los Medios (Landesmedienanstalten)}

La radiodifusión privada en Alemania tiene una larga y compleja historia. A pesar de su desarrollo expansivo hoy en día está en una situación competitiva difícil ${ }^{150}$. Cuando en 1987 se aprobó el Acuerdo Federal para la reorganización de la Radiotelevisión (que sería el primer paso para el primer Acuerdo Federal de Radiotelevisión $(R S t V))^{151}$, se consolidó su existencia como parte del sistema dual de la radiotelevisión alemana: los mismos se convirtieron junto con los medios de comunicación públicos, en garantes del sistema democrático a través de su contribución a la formación de la opinión pública. De esta forma, se exige también al legislador alemán que garantice su existencia ${ }^{152}$.

No obstante, la televisión privada no surgió en las mismas condiciones que la radiotelevisión pública ${ }^{153}$. Era evidente que esta función de servicio público por parte de los medios de comunicación privados debía ser controlada por parte de algún órgano independiente, y así se crearon, a través de Leyes de comunicación, las llamadas Instituciones de los Medios (Landesmedienanstalten). El BVerfG consideró que su existencia era necesaria para garantizar el pluralismo, pero también era consciente de que la financiación del mismo vendría por parte de la publicidad, por lo que las mismas podrían llegar a descuidar la calidad de la programación, y así concluyó que los requisitos normativos para su creación deberían limitarse a comprobar que su organización garantizaba el pluralismo y que, en

149 Vid. 19. ${ }^{a}$ Informe de la KEF, de febrero de 2014 (19. Bericht, Kommission zur Ermittlung des Finanzbedarfs der Rundfunkanstalten. Disponible en http://www.ard.de/download/480202/19_KEF_Bericht_ als_PDF.pdf (Consultado: 6/08/2015), pp. 155-158.

150 Wilke, J., «Die zweite Säule des «dualen Systems»: privater Rundfunk», en $A P u Z$, n. ${ }^{\circ}$ 9-10, 2009, pp. 12-19.

151 «Staatsvertrag zur Neuordnung des Rundfunkwesens «, de 1 a 3 de abril de 1987, que entró en vigor el 1 de diciembre de 1987. Esta idea se recogió en el Staatsvertrag über den Rundfunk im vereinten DeutschlandRundfunkstaatsvertrag (RStV), de 31 de agosto de 1991.

152 BVerfGE 73, 118 (159); y SALVAdor Martínez, M., «El modelo audiovisual...», op. cit., p. 376

153 Al respecto, vid. Hoffmann-RIEM, W./SCHulz, W., «La televisión pública...», op. cit., pp. 62-64. 
todo caso, lo que se debía evitar era la formación de una opinión dominante, lo cual se conseguiría con medidas anticoncentración ${ }^{154}$.

En esta línea, la regulación de las Instituciones de los Medios la vamos a encontrar en cada una de las Leyes o Acuerdos de creación de las mismas, así como en el marco general del Acuerdo Federal de Radiotelevisión y Telemedia ( $R S t V, \S \S 20$ a 47), y en los ya citados Acuerdos relacionados con la contribución a la radiotelevisión (Rundfunkbeitragsstaatsvertrag, $R B S t V$ ) y el relativo a su financiación (Rundfunkfinanzierungsstaatsvertrag, $R$ finSt $V)^{155}$.

Tal y como acabamos de señalar, las emisoras de radiotelevisión privadas requieren de la previa autorización para su puesta en marcha ${ }^{156}$, siendo las Instituciones de los Medios las autoridades encargadas de su gestión ${ }^{157}$, y la Comisión de licencias y supervisión (Kommission für Zulassung und Aufsicht, ZAK) la encargada de la concesión. El proceso de concesión de licencias es relativamente senci$10^{158}$. La única peculiaridad a destacar respecto de otros modelos europeos la podemos encontrar en el exhaustivo control que se ejerce respecto de la garantía del pluralismo y de ahí la exigencia de respeto de medidas anticoncentración y la necesidad de que las propuestas de creación de un nuevo medio superen el llamado Test de los Tres Niveles (Drei Stufen Test) ${ }^{159}$.

La singularidad del sistema alemán consiste en que no es el Estado el que adjudica las concesiones y controla la actividad de las televisiones privadas, sino que para ello se han creado unas Instituciones de Derecho público especiales, independientes y con capacidad jurídica propia: las Landesmedienanstalten. El procedimiento para otorgar una concesión se inicia normalmente con la apertura de un concurso público que convocan las Institucines de los Medios, que son también las que deciden sobre la adjudicación de acuerdo con un conjunto de parámetros previamente establecidos en la Ley ${ }^{160}$. Estas Instituciones de los Medios tienen un régimen jurídico muy similar al de las Instituciones de Televisión del sector público. Las empresas privadas concesionarias deben cumplir determinados requisitos personales y materiales, así como ciertas exigencias relacionadas con su organización y con la gestión de su actividad; exigencias que tratan de asegurar que su programación contribuya a garantizar en la mayor medida de lo posible el pluralismo y la libre formación de la opinión púbica. Entre esas exigencias cabe destacar el nuevo sistema de control de con-

154 Bomas, W., «Der duale Rundfunk...», op. cit., pp. 19 y 21; y HoFFMANN-Riem, W., Regulierung der dualen..., op. cit., pp. 32-33.

155 Hesse, A., Rundfunkrecht. Die Organisation des Rundfunks in der Bundesrepublik Deutschland, 2. ${ }^{\text {a }}$ ed. Hillmoth, Munich, 1999, p. 32 y ss.

$156 \& 20 R S t V$.

$157 \S 36$ y 37 RStV.

158 Sobre el mismo, vid. $\$ 37$ RSt $V$.

$159 \$ 26 .(2) R S t V$, donde se exige que la emisora solicitante no supere el $30 \%$ de cuota de pantalla.

$160 \mathrm{Al}$ respecto, vid., por ejemplo, $\$ \$ 6$ y 7 BremLMG; y $\$ 20$ Medienstaatsvertrag HSH. 
centraciones mediáticas basado no en porcentajes de participación accionarial, sino en las cuotas de audiencia ${ }^{161}$.

Hoy en día existen en Alemania catorce Instituciones de los $\operatorname{Medios}^{162}$ : la Institución estatal de Comunicación de Baden-Württenber (Landesanstalt für Kommunikation Baden-Württember, $L f K)^{163}$; la Central estatal de nuevos medios de Bayern (Bayerische Landeszentrale für neue Medien, BLM) ${ }^{164}$; la Institución de los Medios de Berlin-Brandenburg (Medienanstalt Berlin-Brandenburg, mabb), que junto a Hamburgo y Schleswig-Holstein son las únicas Instituciones creadas por un Acuerdo entre dos Länder y que, por tanto, ejerce sus funciones en el ámbito territorial de los dos, respectivamente ${ }^{165}$; la Institución estatal de los Medios de Bremen (Bremische Landesmedienanstalt, $\left(\mathrm{bre}(\mathrm{ma})^{166}\right.$; la Institución de los Medios de Hamburgo/Schleswig-Holstein (Medienanstalt Hamburg/Schleswig-Holstein, MA $H S H{ }^{167}$; la Institución estatal para la radiotelevisón privada de Hessen (Hessische Landesanstalt für privaten Rundfunk und neue Medien, LPR Hessen ${ }^{168}$; la Institución de Medios de Mecklenburg-Verpommern (Medienanstalt Mecklenburg-Vorpommern, $M M V)^{169}$; la Institución estatal de los Medios de Niedersachsen (Nieders $\ddot{a}$ chischer Landesmedienanstalt, NLM) ${ }^{170}$; la Institución estatal de Medios de Nordr-

161 Salvador Martínez, M., «El modelo audiovisual...», op. cit., p. 376.

162 Berlin y Brandenburgo por un lado, así como Hamburgo y Schleswig-Holstein, comparten respectivamente una Landesmedienanstatel. Por eso el número es 14, no 16, el de los Länder. Sobre este grupo conjunto, vid. la web oficial de la Institución de los Medios que las reúne a todas (la ALM, Die Medienanstalten) http://www.die-medienanstalten.de/ueber-uns/aufgaben.html (Consultado: 06/07/2015).

163 Vid. http://www.lfk.de/; y Ley estatal de Medios de Baden-Württemberg (Landesmediengesetz Baden-Württemberg, LMedienG), de 19 de julio de 1999, modificada última vez el 3 y el 11 de diciembre de 2013.

164 Vid. http://www.blm.de/de/startseite.cfm; y Ley para el desarrollo, promoción y organización de la oferta privada radiotelevisiva y otros servicios telemáticos en Bayern — Ley de Medios de Bayern (Gesetz über die Entwicklung, Förderung und Veranstaltung privater Rundfunkangebote und anderer Telemedien in Bayern Bayerisches Mediengesetz, BayMG), con la redacción de 22 de octubre de 2003, modificada última vez el 22 de mayo de 2015 .

165 Vid. http://www.mabb.de/; y Acuerdo estatal de colaboración entre Berlín y Brandemburgo en el ámbito de la radiotelevisión (Staatsvertrag über die Zusammenarbeit zwischen Berlin und Brandenburg im Bereich der Medien, MStV) de 29 de febrero de 1992, con la redacción de la quinta modificación del citado Acuerdo, de 30 de agosto/11 septiembre 2013 (entrada en vigor el 1 de enero de 2014).

166 Vid. http://www.bremische-landesmedienanstalt.de/; y Ley estatal de los Medios de Bremen (Bremisches Landesmediengesetz, BremLMG), de 26 de noviembre de 2013, revisada el 12 de agosto de 2015.

167 Vid. http://www.ma-hsh.de/die-ma-hsh/; y Acuerdo estatal sobre Derecho de los Medios en Hamburgo y Schleswig-Holstein — Acuerdo estatal de los Medios (Staatsvertrag über das Medienrecht in Hamburg und Schleswig-Holstein — Medienstaatsvertrag HSH), de 13 de junio de 2006, con la redacción de la quinta modificación del citado Acuerdo, de 2/22 de septiembre de 2014.

168 Vid. http://www.lpr-hessen.de/; y Ley sobre la Rediotelevisión privada en Hessen — Ley de radiotelevisión privada de Hessen (Gesetz über den privaten Rundfunk in Hessen - Hessisches Privatrundfunkgesetz, HPRG), con la redacción de 25 de enero de 1995, modificada última vez el 29 de noviembre de 2014.

169 Vid. http://www.medienanstalt-mv.de/home/index.html; y Ley de Radiotelevisión para el Land Mecklenburg-Vorpommern (Rundfunkgesetz für das Land Mecklenburg-Vorponmmern, RundfG-M-V), de 20 de noviembre de 2003, modificada última vez el 20 de abril de 2015.

170 Vid. http://www.nlm.de/; y Ley de los Medios de Niederschachsen (Niedersächsisches Mediengesetz, NMedien $G$ ), de 11 de octubre de 2010. 
hein-Westfalen (Landesanstalt für Medien Nordrhein-Westfalen, $L f M)^{171}$; la Central estatal para los Medios y la Comunicación de Rheinland-Pfalz (Landeszentrale für Medien un Kommunikation Rheinland-Pfalz, $L M K)^{172}$; la Institución estatal de Medios de Saarland (Landesmedienanstalt Saarland, $L M S)^{173}$; la Institución estatal de televisión privada y nuevos medios de Sachsen (Sächsische Landesanstalt für private Rundfunk und neue Medien, SLM $)^{174}$; la Institución de Medios de Sachsen-Anhalt (Medienanstalt Sacbsen-Anbalt, MSA) ${ }^{175}$; y la Institución estatal de Medios de Thüringer (Thüringer Landesmedienanstalt, TLM) ${ }^{176}$.

En el sector privado radiotelevisivo son dos grandes grupos los que comenzaron a ofrecer sus servicios entre 1984 y 1985 — con la apertura del sistema dual - y a ofrecer la programación completa. Nos referimos a SAT1 y RTL Plus. Unos años más tarde, en torno a 1989, comenzó su programación Pro7 (anterior Eureka TV) y Tele5 (la anterior Musicbox, actual DSF). Y en los años 1992 y 1993, y a partir de este momento, se van a establecer en el mercado dos grandes canales generalistas (RTL2 y Pay-TV: Premiere) y seis canales temáticos ( $n-t v$, Vox, Kabelkanal (Kabel 1), VIVA, DSF y Pro7). Por su parte, la emisión de nuevos programas de radio requerirá de la previa aprobación — siempre que lleguen a más de quinientos oyentes - ${ }^{177}$, excepto si su emisión es exclusivamente a través de Internet ${ }^{178}$. La emisión de nuevos programas deberá cumplir, en todo caso, con las previsiones previstas en el $R S t V^{179}$.

Las Instituciones de los Medios están obligadas a cooperar entre sí para el cumplimiento de sus funciones y para la defensa de sus intereses ${ }^{180}$ : en primer lugar, para evitar que la regulación que pueda aprobar cada Land — que son los que tienen competencia en la materia - siga criterios diferentes tanto a la hora

171 Vid. http://www.lfm-nrw.de/; y Ley estatal de los Medios de Nordrhein-Westfalen (Landesmediengesetz Nordrbein-Westfalen, LMG NRW), de 2 de julio de 2002, modificada última vez el 18 de diciembre de 2014 (entrada en vigor el 23 de enero de 2015).

172 Vid. http://www.lmk-online.de/; y Ley estatal de los Medios (Landesmediengesetz, LMG), de 4 de febrero de 2005, con la redacción de 20 de diciembre de 2013.

173 Vid. https://www.Imsaar.de/; y Ley de los Medios de Saarland (Saarländisches Mediengesetz, SMG), de 27 de febrero de 2002, modificada última vez el 19 de septiembre de 2012.

174 Vid. http://www.slm-online.de/; y Ley sobre Radiotelevisión privada y Nuevos medios en Sachsen — Ley de Radiotelevisión privada de Sachsen (Gesetz über den privaten Rundfunk und neue Medien in Sachsen Sächschische Privarundfunkgesetz, SächsPRG), con la redacción consolidada de 9 de enero de 2001, modificada última vez el 29 de abril de 2015 (entrada en vigor el 9 de mayo de 2015).

175 Vid. http://www.msa-online.de/; y Ley de los Medios del Land Sachsen-Anhalt (Mediengesetz des Landes Sachsen-Anhalt, Medien G LSA), de 2 de enero de 2013, modificada última vez el 5 de diciembre de 2014

176 Vid. http://www.tlm.de/tlm/; y Ley estatal de los Medios de Thüringen (Thüringer Landesmedienkgesetz, ThürLMG), de 15 de julio de 2014 (en vigor el 30 de julio de 2014).

$177 \S 2 .(3) .1 \mathrm{RStV}$.

$178 \S 20 \mathrm{~b} R S t V$. La no notificación puede ser perseguida como un delito menor (vid. $\S 18 R S t V$ ).

$179 \$ \S 11$ c y $11 \mathrm{f} R S t \mathrm{~V}$, relativos, respectivamente a los Programas de radio de la ARD y de Deutschlandradio, así como a la oferta de nuevos programas. Sobre la oferta radiotelevisiva privada, vid. HermanN, K., «Den öffentlich-rechtliche...», op. cit., pp. 19-20.

180 BVerfGE 73, 118 (196 y ss.). 
de otorgar las concesiones como para controlar la programación; y, en segundo lugar porque la emisión de las televisiones privadas no se centra en un determinado ámbito territorial, sino que se emite para toda la Federación o incluso para el extranjero, siendo conveniente regular los intereses comunes al respecto. Con el fin de potenciar y desarrollar la citada cooperación se han creado distintas asociaciones, comisiones o comités, con la función de elaborar directrices en materias como la protección de la juventud, la publicidad, el patrocinio o los nuevos servicios de comunicación. Esta cooperación tendrá su máxima expresión en la Asociación creada a tal efecto por las citadas Instituciones, la Medienanstalten, ALM.

Finalmente debemos señalar que en los últimos años, las cadenas privadas se han visto sometidas a una serie de críticas relacionadas con su falta de imparcialidad, la escasez de planteamientos críticos y la priorización del espectáculo. Es cierto que el Gobierno no puede exigir mucho a estos medios privados, pero debemos recordar que deben cumplir con la normativa y mantener la independencia, en tanto que como señaló el BVerfG, las mismas colaboran en la función de servicio público de radiotelevisión ${ }^{181}$.

\section{A) Organización interna}

Al igual que las Instituciones de Radiotelevisión, las Instituciones de los Medios se han creado como instituciones de derecho público a las que se les ha atribuido autonomía y a las que se reconoce como titulares del derecho fundamental a la libertad de los medios. Las Instituciones de los Medios también disfrutan de potestad reglamentaria para regular su organización interna y su funcionamiento en el marco de lo establecido por la Ley. Por regla general, por lo tanto, estas Instituciones siguen el esquema de organización interna de las Instituciones de Radiotelevisión, es decir, se componen de un órgano colegiado, normalmente denominado Asamblea (formado por representantes de los grupos sociales más relevantes); en algunos casos, por un Consejo de Administración; y por último, por un órgano, normalmente unipersonal (el Director), que desempeña las funciones de dirección y representación (lo que era el Intendente). Las personas que forman parte de estos órganos, por regla general, son nombradas por los Parlamentos de los Länder y por representes de los grupos sociales más importantes.

\section{a) La Asamblea (Versammlung)}

Mientras en unos casos esta Asamblea es una gran Comisión, en otros es un Consejo reducido. Así, el número de miembros va a variar, desde 11 hasta $50^{182}$. En

181 BVerfGE 73, 118 (159). BayMG).

182 Los 11 de la Institución de Mecklenburg y los 50 de la de Bayer (§52 RundfG M-V; y art. 13 
el caso de una Asamblea de gran tamaño, en todo caso, será el legislador a través de la norma de creación de la Institución el que determine qué grupos y en qué proporción tendrán representación en este órgano ${ }^{183}$. Para el caso de que la Asamblea sea de reducido tamaño, entre 5 y 7 miembros, normalmente son nombrados por el Parlamento del Land entre personas con reconocida experiencia en el ámbito de los medios de comunicación. En el caso de una Asamblea reducida, su composición no parece responder estrictamente al principio del pluralismo interno (ya que los consejeros no son representantes elegidos directamente por los grupos sociales más relevantes), por lo que para garantizar la independencia de sus miembros, se exige que el Parlamento los elija por mayoría reforzada de dos tercios, no siendo posible la reelección ${ }^{184}$. En este sentido, para garantizar la autonomía de los miembros de esta Asamblea se establece un estricto régimen de incompatibilidad, prohibiéndoles formar parte del Gobierno, del Parlamento, de una Institución de Radiotelevisión o de una empresa privada concesionaria ${ }^{185}$. Su mandato dura de 4 a 6 años, según los $\operatorname{casos}^{186}$, sin que éstos puedan ser cesados ${ }^{187}$. Por otro lado, en relación con sus funciones, además de las propias de aprobación de sus Estatutos y su presupuesto, la relacionada con la decisión de adjudicación, revocación y anulación de concesiones, así como la aplicación de sanciones cuando así corresponda ${ }^{188}$.

\section{b) El Consejo de Administración (Vorstand)}

En relación con el Consejo de Administración, su creación es discrecional por parte de la Institución, siendo muy pocas las que así lo han hecho ${ }^{189}$. Se trata de un órgano elegido por la mencionada Asamblea. Este Consejo se ha organizado del mismo modo y con las mismas competencias que el Consejo de Administración de las Instituciones de Radiotelevisión. Su principal competencia es controlar la actividad económica de la Institución.

\section{c) El Director (Direktor)}

Finalmente, la figura que sí que se ha creado en la mayoría de las Instituciones de los Medios es un órgano ejecutivo unipersonal semejante al Intendente de

183 BVerfGE 57, 295 (325); y 83, 238 (335); y, por ejemplo, § 62 LMG NRW.

184 Este modelo existe en Berlin-Brandenburg ( $\$ 10$ y $11 \mathrm{MStV}$ ) y en Baden-Württember $(\S 41$ LMedien G).

185 Entre otras diposiciones, por ejemplo, art. 13.(2) BayMG; y $\S$ 64.(2) LMG NRW.

186 Vid., por ejemplo, § 42.(6) ThürLMG; § 9.(4) MStV; y § 42.(9) MedienG LSA.

187 Por ejemplo, en el § 41.(4) y (5) LMedienG; y $\$$ 49.(3) BremLMG.

188 Por ejemplo, art. 12 BayMG; 51 BremLMG; y $\$ 53$ RundfG MV.

189 Por poner un ejemplo, vid. arts. 10 y 14 BayMG; y $\S 25$ y 31 SMG. 
las Instituciones de Radiotelevisión. Este órgano recibe denominaciones diferentes: Director, Presidente, Administrador General o Gerente. No obstante, no faltan casos en los que esta figura ejecutiva es un órgano colegiado y se compone de 2 a 5 miembros elegidos por la Asamblea de la Institución o por el Parlamento del Land mediante mayoría reforzada de dos tercios ${ }^{190}$. Esto se hace para que, en la medida de lo posible, los elegidos no tengan que depender de los partidos politicos ${ }^{191}$. Por otro lado, en relación con las funciones de este órgano, el mismo se encarga de representar a la Institución, de presentar los presupuestos y cuentas anuales a la Asamblea, así como de controlar la programación y la publicidad del medio $^{192}$.

d) La organización de la Institución de los Medios (Die Medienanstalten, ALM)

Tal y como sucedía en el sector público con la ARD, que estaba constituida por las diferentes Instituciones de Radiotelevisión, las Instituciones estatales de los Medios se coordinan a través de la conocida Institución de los Medios (Die Medienanstalten). Este organismo, a través de diferentes Gremios, Conferencias y Comisiones, se encarga de coordinar las funciones básicas de la radiotelevisión privada en Alemania. La dirección y coordinación de las citadas Comisiones en el seno de la $A L M$ la ostentará la llamada «Oficina central de las Instituciones de los Medios» (Gemeinsame Geschäftsstelle). Teniendo en cuenta que la función principal de las Instituciones de los Medios es la gestión de la autorización o licencia, el control de la programación y de la concentración, la citada Oficina se encargará de coordinar dichas funciones.

Las funciones de esta Institución conjunta, la $A L M$, que en realidad es una Asociación, se encuentran recogidas en su Estatuto ${ }^{193}$. Asimismo, esta Asociación cuenta con una serie de recursos económicos para su mantenimiento y desarrollo de sus funciones ${ }^{194}$.

Un órgano importante de coordinación dentro de esta Institución es la Conferencia del Comité de Presidentes de las Instituciones de los Medios (la Gremien-

190 En los casos de órgano ejecutivo colegiado, el Pleno elige a uno de los miembros para desempeñar el cargo de Presidente y a otros dos para ejercer las funciones de Vicepresidente (por ejemplo, § $44 L M G$ ).

191 Sólo en dos Instituciones de los Medios este órgano ejecutivo no es elegido por la Asamblea de la Institución, sino por el Parlamento del Land: en Saarland y Baden-Württemberg (§ 58.(1) SMG; y $§$ 36.(1) LMedien G).

192 Entre otras disposiciones, art. 15.2 BayMG; y $\$ 103$ LMG NRW.

193 Contrato para el trabajo conjunto de la Asociación de las Instituciones de los medios en la República federal alemana, de 20 de noviembre de 2013 (Vertrag über die Zusammenarbeit der Arbeitsgemeinschaft der Landesmedienanstalten in der Bundesrepublik Deutschland - ALM-Statut).

194 \$ 4 ALM-Statut; y Acuerdo de la ALM para cubrir sus funciones — Estatuto Financiero de la ALM (Übereinstimmende Satzung der Landesmedienanstalten zur Deckung der notwendigen Ausgaben/Aufwendungen der Organe nach $\$ 35$ Absatz 2 des Rundfunkstaatsvertrags und zur Erfüllung der Gemeinschaftsaufgaben (Finanzierungssatzung — FS), de 20 de noviembre de 2013 (en vigor desde el 1 de julio de 2014). 
vorsitzendenkonferenz, $G V K$ ), formada por los Presidentes de las distintas Instituciones de los Medios, y que tiene la misión de tomar decisiones sobre la disponibilidad técnica existente a la hora de adjudicar las licencias ${ }^{195}$, aunque también se encarga de asesorar a las Instituciones sobre el desarrollo digital, la convergencia de medios y los principios éticos que deben inspirar la programación. La Conferencia elegirá a su Presidente de entre sus miembros ${ }^{196}$.

Junto a la anterior Comsión, destaca la Conferencia de Directores (Direktorenkonferenz der Landesmedienanstalten, DLM), que se compone de los representantes legales (Directores o Presidentes) de cada una de las catorce Instituciones de los Medios. Dicha Conferencia representa los intereses de las Instituciones de los Medios respecto de intercambio de información más allá de las tareas de certificación y supervisión ${ }^{197}$. Dentro de la organización de la DLM nos vamos a encontrar con la Conferencia Técnica de las Instituciones de los Medios (Technische Konferenz der Landesmedienanstalten, TKLM). Entre sus funciones se encuentra analizar las cuestiones relacionadas con la digitalización de los medios, así como el asesoramiento para el paso de la tecnología analógica a la digital.

Como órgano de reunión de las anteriores Conferencias y encargada de las cuestiones relacionadas con la programación y su asesoramiento, encontramos la Conferencia General (Gesamtkonferenz, GK), compuesta por la Conferencia de directores (DLM) y por la Conferencia del Comité de Presidentes (GVK). Además de asesorar sobre cuestiones relacionadas con la publicidad en un sistema dual de radiotelevisión, se encarga de mediar y resolver los conflictos de competencia que se produzcan entre las Comisiones ${ }^{198}$.

\section{B) Competencias y funciones}

Las Instituciones de los Medios desarrollan su actividad en el ámbito de la televisión privada y su función consiste en garantizar la libertad de televisión y, por tanto, la formación libre de la opinión pública en este ámbito. Como ocurría con la televisión pública, estas Instituciones no cumplen con una función estatal, sino más bien con un servicio público ${ }^{199}$. Así, disfrutan de autonomía funcional, llevan a cabo la función que les compete bajo su entera responsabilidad, sin recibir órdenes ni instrucciones de ninguno de los órganos del Estado ${ }^{200}$.

Entre sus funciones: la potestad normativa (previa habilitación legal cuando se trate de regular a las empresas privadas audiovisuales), y la potestad sanciona-

$195 \S 36.3 R S t V$.

$196 \$ \S 3$ y 3 a ALM-Statut.

$197 \$ \S 3$ y 3 a ALM-Statut.

$198 \$ \S 3$ y 3 a ALM-Statut.

199 Por todos, BVerfGE 57, 295 (326-327); y 73, 118 (160 y ss.)

200 Así, BVerfGE 73, 118 (165); y, por ejemplo, §§ 24-26 LMG; y §§ 7-15 ThürLMG. 
dora ${ }^{201}$. Pero una de las funciones más importantes es la de adjudicar las concesiones de televisión privada y de controlar la actividad de estas televisiones ${ }^{202}$. En el ordenamiento jurídico alemán todo sujeto que quiera emitir radiotelevisión necesita obtener previamente una concesión ${ }^{203}$. Según el $B V \operatorname{erf} G$, el establecimiento de un régimen de concesiones es conforme con la Ley Fundamental, ya que garantiza la independencia de las emisiones privadas frente al Estado.

Por su parte, el Acuerdo federal sobre Radiotelevisión (RStV) establece diversos tipos de concesiones y los principios que deben respetar los Länder al respecto ${ }^{204}$ : la contribución al pluralismo, y, por otro lado, el grado de cobertura de la información política, económica y cultural del Land. Para los medios de comunicación audiovisual privados ha sido creada, entre todas las Instituciones de los Medios, una Comisión encargada de la supervisión y concesión de licencias, la ya citada Kommission für Zulassung und Aufsicht, ZAK ${ }^{205}$.

En relación con la concesión de licencias, las Instituciones están encargadas, además, de proporcionar a las empresas concesionarias todos aquellos medios técnicos necesarios para difundir sus programas, es decir, tienen que proporcionar y promover la infraestructura técnica terrestre en el ámbito regional del Land correspondiente. Así, en el ámbito del Land se encargan de crear y mantener los llamados «canales abiertos» $\mathrm{O}$ «independientes» ${ }^{206}$, así como formas especiales de radiotelevisión local y la gestión de los servicios de cable ${ }^{207}$.

\section{C) Dirección económica y financiación}

En relación con la dirección económica de estas Instituciones, las mismas gozan de autonomía presupuestaria: ellas mismas elaboran su propio presupuesto y disfrutan, también, de autonomía en la dirección y gestión económica de la Institución, y suelen rendir cuentas al Gobierno del Land correspondiente ${ }^{208}$.

En el caso de la financiación, como en el caso de las Instituciones de Radiotelevisión, el legislador ha optado aquí por establecer un sistema mixto de financiación. Los ingresos de estas Instituciones provienen: en primer lugar, de la $R S t V$.

201 BVerfGE 33, 125 (157 y ss.). Sobre el régimen jurídico de las televisiones privadas, §§ 33 y 46

202 BVerfGE 57, 295 (326)

$203 \S 20$ RStV; y, por ejemplo, § 12.(1) LMedienG; y § 3.(1) BremLMG.

$204 \S \$ 20$ a $24 R S t V$.

205 Sobre la misma, para más información, vid. http://www.die-medienanstalten.de/ueber-uns/organisation/kommission-fuer-zulassung-und-aufsicht-zak.html (Consultado: 06/07/2015).

$206 \$ 31$ RStV; y Directrices de los Terceros independientes (Gemeinsame Richtlinien der Landesmedienanstalten über die Sendezeit für unabbängige Dritte nach \$31 RStV (Drittsendezeitrichtlinie — DSZR)), de 16 de diciembre de 1997, en la redacción del Acuerdo de la $D L M$ de 14 y 15 de septiembre de 2004.

207 Por ejemplo, \$§ 36 a 41a MStV; §53 SMG; y $\$ 16$ LMedienG.

208 Entre otras, vid., por ejemplo, $\$ \$ 46$ y 47 LMedien $G$; y art. 21 BayMG. 
contribución de radiotelevisión, de acuerdo con una proporción establecida en el Acuerdo Federal de Radiotelevisión (Rundfunkstaatsvertrag, $R S t V)^{209}$; y, en segundo lugar, de otros conceptos por los que se debe pagar a las empresas privadas de televisión, como la publicidad ${ }^{210}$. En este caso, como en las televisiones públicas, son las propias Instituciones de los Medios las que se encargan de regular estos ingresos, aunque siempre dentro del marco de lo establecido en las Leyes de los Medios que los crean ${ }^{211}$, interviniendo a tal efecto la ya citada $K E F$ respecto de la determinación de la cuantía a otorgar. Para asegurar la independencia y no manipulación por parte de los poderes públicos, que se exige por la libertad de los medios de comunicación, se debe asegurar, como mínimo, de un $1 \%$ a un $2 \%$ de la cantidad recaudada con la contribución por radiotelevisión ${ }^{212}$.

Desde la apertura al sector privado en 1984, la televisión alemana se ha convertido en uno de los más lucrativos del mundo, especialmente desde la gran variedad de canales ofertados ${ }^{213}$. No obstante, la radiotelevisión privada se financia esencialmente de la publicidad. Desde la modificación del $R S t V$ de 1 de julio de 2002, los operadores privados de radiotelevisión pueden financiar su programación a través de los ingresos de publicidad y televenta, y a través de diferentes ingresos, especialmente de los abonos o cuotas de sus usuarios, y de sus propios medios, no estando autorizada una financiación exclusiva a base de la tasa de radiotelevisión ${ }^{214}$. De la misma forma se prevé en las Leyes de creación de las citadas Instituciones que la fuente de financiación de la radiotelevisión privada será la publicidad, permitiéndose fórmulas mixtas como la televisión de pago por programa (pay-tv) con los programas comerciales o el sponsoring de programas ${ }^{215}$.

\section{LOS SERVICIOS TELEMEDIA}

En Alemania, junto a la regulación de la radiotelevisión se ha incluido la regulación de los servicios telemedia, entendiendo éstos como aquellos servicios de información y comunicación que se prestan por medios electrónicos, al margen de las conocidas telecomunicaciones y dejando también al margen la prensa escrita $^{216}$. La regulación de los servicios telemedia se encuentra en el ya citado

$209 \S \S 10$ y 11 Rundfunkfinanzierungsstaatsvertrag, RfinSt $V$; y también, $§ 40 R S t V$.

210 Así, por ejemplo $\$ 46$ LMedien $G$; y $\$ 46$ y 48 LMG.

211 Así, por ejemplo, §49 LMG; y $\$ 16 \mathrm{MStV}$.

$212 \S 40$ RStV; Bomas, W., «Der duale Rundfunk...», op. cit., p. 25; y Hoffmann-Riem, W., Regulierung der dualen..., op. cit., p. 36.

213 Vid. Fenske, U./Trkulja, V., «VI. Medien in...», op. cit., pp. 76-77, quienes recuerdan que en 2004 había en Alemania 33.720.000 hogares con televisión registrados.

$214 \S \$ 40$ y 43 RStV.

215 Bomas, W., «Der duale Rundfunk...», op. cit., pp. 26-27.

$216 \S 1.1$ Telemediengesetz, TMG. 
Rundfunkstaatsvertrag (RStV) — concretamente en su VI Apartado, $\S \S 54$ a 61—, y en la Ley de Servicios telemedia (Telemediengesetz) ${ }^{217}$.

Lo peculiar de estos servicios es el hecho de que cualquier oferta radiotelevisiva que se quiera hacer a través de servicios telemedia, ya sea por parte de la ADR, ZDF o Deutschlandradio, tendrá que ser analizada por la KEF con el citado Test de los Tres Niveles (Drei Stufen Test), con el fin de comprobar si la nueva propuesta se ajusta a los principios de la radiotelevisión, no pone en peligro el pluralismo, y es «representativa» ${ }^{218}$. Al margen de las nuevas propuestas de programas, las citadas cadenas públicas podrán ofrecer sus contenidos a través de estos nuevos servicios ${ }^{219}$, en tanto que los servicios telemedia no requieren previa autorización, aunque sí notificación ${ }^{220}$. Es una forma más de ofrecer los servicios radiotelevisivos. No obstante, hay que señalar aquí que los servicios telemedia tienen prohibida la publicidad y el sponsoring 221 .

El control de este tipo de servicios, además de los ya citados, se basará en el respeto general a las leyes, en concreto a las relativas al respeto al honor y a la protección de datos personales, donde el control podrá ser ejercido por la autoridad independiente competente ${ }^{222}$.

\section{LOS MECANISMOS DE CONTROL DE LOS MEDIOS DE COMUNICACIÓN}

Los mecanismos de control de los medios de comunicación en Alemania, si bien existen como en la mayoría de los Estados de la Unión Europea — donde la regla general es la existencia de una Autoridad de control independiente-, se van a centrar en controlar el respeto al pluralismo en sus diversas manifestaciones, en la protección de la intimidad, así como en proteger a los sectores sociales más vulnerables, como infancia y juventud ${ }^{223}$.

De acuerdo con el Tribunal Constitucional federal, los mecanismos de control tienen que evitar que el Estado influya de forma determinante en la actividad de las radiotelevisiones ${ }^{224}$. Por lo tanto, el control de los medios de comunicación en Alemania se caracteriza por tres notas: la primera, que el control estatal se limita a un control jurídico, no político, es decir, se ejerce teniendo como parámetro una norma jurídica precisa y nunca razones de oportunidad. Cualquier forma

217 Telemediengesetz, TMG, de 26 de febrero de 2007 (última modificación el 17 de julio de 2015).

$218 \S \S 11 \mathrm{f}$ y 54 .(3) $R S t V$.

$219 \S 11$ d.(4) $R S t V$.

$220 \$ \$ 54 .(1)$ y $61 R S t V$.

$221 \S \S 11$ d.(5) y $58 R S t V$.

$222 \S \S 59 .(2)$ y $57 R S t V$.

223 Carrillo López, M., «Las televisiones públicas...», op. cit., p. 240.

224 BVerfGE 12, 205 (261). 
de control político supondría permitir que los poderes públicos influyeran decisivamente en la actividad televisiva. La segunda, que el control estatal es limitado, consistente exclusivamente en la posibilidad de presentar un recurso en vía administrativa cuando se entienda que una televisión ha cometido una determinada infracción jurídica. Y, la tercera, que el control estatal es subsidiario de los mecanismos de control que funcionan en el interior de las Instituciones de Radiotelevisión ${ }^{225}$.

Por último, junto a los órganos de control propios de los medios de comunicación, se han creado autoridades de control independientes encargadas de controlar materias específicas, como las relacionadas con el tratamiento de datos personales (Bundesbeauftragte für den Datenschutz und die Informationsfreibeit) o para la protección del menor la Oficina federal para los Medios de comunicación perjudiciales para los menores (Bundesprüfstelle für jugendgefäbrdende Medien, BPjM) ${ }^{226}$.

\section{Prensa}

En 1956, con sede en Berlín, se creó, con 10 miembros, el Consejo Aleman de la Prensa (Deutsche Presserat, DP) por parte de la Asociación de periodistas de Alemania (Deutscher Journalisten-Verband, DJV) y la Asociación federal de editores de periodicos de Alemania (Verband Deutscher Zeitschriftenverleger, VDZ) ${ }^{227}$. Tras la adhesión en 1957 de la Asociación de editores de revistas de Alemania (Bundesverband Deutscher Zeitungsverleger, BDZV) y de la Uniónn de Periodistas de Alemania (Deutsche Journalistinnen- und Journalisten-Union, dju) en 1960, con el fin de garantizar la paridad entre representantes de periodistas y editores, el número de miembros del Consejo aumentó a 20 (10 representantes de editores ( 5 de periodicos y 5 de revistas) y 10 representantes de periodistas). Actualmente está compuesto por 28 miembros de cada una de las cuatro Asociaciones que lo integran. Sus miembros son nombrados por un periodo de dos años, siendo posible su renovación ${ }^{228}$.

La organización del Presserat gira en torno a una Asamblea General y una Junta Ejecutiva ${ }^{229}$. Para garantizar la independencia del Consejo, en 1976 se aprobó una Ley en relación con su financiación y con este único y exclusivo obje-

225 Salvador Martínez, M., «El modelo audiovisual...», op. cit., p. 375.

226 Vid. http://www.bfdi.bund.de/DE/Home/home_node.html y http://www.bundespruefstelle.de/.

227 http://www.presserat.de/presserat/ (Consultado: 06/07/2015). Para su regulación, vid. Estatuto del Presserat (Satzung und Geschäftsordnung des Deutschen Presserats), de 25 de febrero de 1985, en la redacción de 3 de marzo de 2010. Sobre este órgano, vid. Löffler, J., «Standesrecht der Presse, Presse-Selbstkontrolle, Deutscher Presserat «, en Presserecht, 5. ${ }^{a}$ ed., Beck, Munich, 2006, pp. 1089-1091 (pp. 1079-1096); y PopTCHEVA, E.V., «Las autoridades independientes...», op. cit., pp. 304-308.

228 § 2 y 7 Satzung und Geschäftsordnung des Deutschen Presserats.

$229 \S \S$ 3-6 Satzung und Geschäftsordnung des Deutschen Presserats. 
to $^{230}$. A tal efecto, se dispone expresamente que el Consejo debe recibir de la Federación una cantidad en forma de subvención anual ${ }^{231}$. Asimismo, el Consejo se financia a través de las contribuciones que recibe de las cuatro Asociaciones que lo integran.

En relación con sus competencias y funciones, el Presserat no tiene competencia alguna sobre los medios de comunicación audiovisual, sino sobre la prensa escrita. No obstante, desde el año 2009, también tiene competencia sobre la prensa digital $^{232}$. El Consejo tiene como misión esencial velar por la protección de la libertad de prensa, por el libre acceso a las fuentes de información, controlar posibles concentraciones y monopolios, así como defender los intereses de la prensa en las propuestas legislativas. Pero entre sus funciones destaca, por encima de todas, el control del cumplimiento de los criterios éticos en la actuación de la prensa escrita, esto es, la observancia del Pressekodex ${ }^{233}$. Debemos destacar que junto a estas competencias el Presserat tiene competencia inspectora y sancionadora en función de la que podrá imponer una desaprobación o reproche (medidas sujetas, claro está, a revisión judicial) ${ }^{234}$. Si bien inicialmente estas sanciones carecían de toda eficacia, a finales de 1985 se llegó a la conclusión de la importancia de ejercer una verdadera función de autorregulación y autocontrol de la prensa ${ }^{235}$. Y así, se crearon una serie de Comsiones para resolver las quejas presentadas, con el fin de controlar que la noticia debe darse de forma objetiva conforme a unos criterios éticos ${ }^{236}$. Incluso en casos en que los reproches del Presserat no han quedado claros y podrían inducir a error al lector, se ha obligado al Consejo a rectificar su reproche ${ }^{237}$.

Para concluir debemos decir que se ha puesto en tela de juicio en más de una ocasión la eficacia de las medidas de control del cumplimiento del Código ético del Presserat. El fundamento de las críticas venía sustentado, por un lado, en la composición de las Comisiones que deben resolver las quejas presentadas, evidenciado por el bajo número de reproches efectuados. Y por otro lado, se criticaba la

230 Ley para garantizar la independencia del Consejo de la Prensa alemán (Gesetz zur Gewährleistung der Unabhängigkeit des vom Deutschen Presserat eingesetzten Beschwerdeausschusses), de 18 de agosto de 1976.

231 La subvención, pasó de 80 marcos alemanes anuales en 1976 a 223 euros en 2010. Vid. arts. 1.2 y 3 Gesetz zur Gewährleistung der Unabhängigkeit des vom Deutschen Presserat eingesetzten Beschwerdeausschusses.

232 § 9 Satzung und Geschäftsordnung des Deutschen Presserats.

233 Vid. http://www.presserat.de/fileadmin/user_upload/Downloads_Dateien/Pressekodex_bo_ web_2015.pdf (Consultado: 7/06/2015). Modificado en marzo de 2005.

234 Sobre el margen de discrecionalidad del Presserat, vid. Sentencia del Landesgericht de Hamburgo, de 17 de diciembre de 1959 (5 U 141 (142) (143)/1959); Sentencia del Landesgericht de Colonia, de 11 de julio de 2006 (15 U 30/06); y Sentencia del Landesgericht Bonn de 26 de enero de 2006 (9 O 420/05).

235 Todo esto surgió en medio de un conflicto entre editores y periodistas por la negativa del Presidente de la Asociación Federal de Editores de Periódicos en Alemania de publicar un reproche. Vid. DIETrich, N., Der Deutsche Presserat, Nomos Verlag, Baden-Baden, 2002, pp. 14 y 15.

236 BVerfGE de 9 de octubre de 2000 (1 BvR 1839/95).

237 Por ejemplo, la Sentencia del Landesgericht de Frankfurt am Main, de 5 de junio de 2007 (2703 O 692/06). 
falta de un mecanismo para hacer efectivas sus sanciones, lo que provocaba que, en más de una ocasión, los grandes medios periodísticos no quisieran publicar los reproches efectuados.

En el terreno de la prensa escrita, en relación con las medidas anticoncentración, la prensa se somete a las mismas reglas que el resto de medios de comunicación privados, al control de la Comisión para la comprobación de la concentración en el ámbito de los medios de comunicación (Kommission zur Ermittlung der Konzentration im Medienbereich, KEK), que se encarga de garantizar la pluralidad de opiniones en las empresas relacionadas con los medios de comunicación privados.

\section{Radio, Televisión y Servicios telemedia}

Además de las Instituciones de Radiotelevisión, así como de las Instituciones de los Medios, y los órganos internos de las mismas - encargados de la gestión y control del servicio público de radiotelevisión-, existen Comisiones, Comités o Asociaciones externos a las mismas y encargados del control de aspectos específicos de los medios de comunicación.

Recordamos brevemente que las Instituciones de Radiotelevisión cuentan con un sistema de control interno - a través del Rundfunkrat, del Verwaltungsrat y del Intendant — de su programación y su financiación, destinado a garantizar el pluralismo ${ }^{238}$. En este sentido, recordamos también que junto al control económico de las Instituciones existe, además, un control jurídico, que en ningún caso deberá versar sobre razones de oportunidad o conveniencia ${ }^{239}$, y mediante el cual el Estado (que no deja de ser el último responsable de garantizar el respeto a la libertad de los medios de comunicación), de forma subsidiaria al control por parte de las Instituciones, fiscaliza a la Institución. Todo ello, como es lógico y como ha reiterado el $B \operatorname{Verf} G$, sin que el Estado influya en los medios de comunicación ${ }^{240}$. La idea es que el Estado sólo intervenga cuando los órganos encargados de fiscalizar a la Institución no cumplen con su obligación ${ }^{241}$. Por lo que se refiere a las Instituciones de los Medios, recordamos aquí que su función es controlar, a través de sus órganos internos (Versammlung, Vorstand y Direktor) a las empresas privadas concesionarias del servicio público de radiotelevisión. En concreto, el

238 Vid. BVerfGE 12, 205, de 26 de febrero de 1961.

239 Las leyes de los Länder contienen regulaciones diferentes y así en unos casos este control se prevé y califica como control jurídico ( $\$ 37$ NDR-StV); y, en otras se excluye expresamente el control estatal ( $\$ 1 .(1)$ HR-G).

240 BVerfGE 12, 205 (261); y 57, 295 (326).

241 Así se establece, por ejemplo, expresamente en el $\$$ 54.(4) WDR-G, pudiéndose llegar a presentar recursos contencioso-administrativo en caso de ignorar las advertencias. En este sentido, por ejemplo, $\S 37$. (3) NDR $-S t V$. 
objeto de control es el cumplimiento de los requisitos de programación ${ }^{242}$, y el respeto a las medidas anticoncentración ${ }^{243}$. En relación con el sector privado, el legislador ha establecido un catálogo de infracciones administrativas en que puede incurrir una empresa privada de televisión, y que las Instituciones de los Medios son las competentes para apreciar la existencia o no de las mismas y aplicar la sanción correspondiente ${ }^{244}$. Así, si la Institución considera que la empresa concesionaria ha incumplido alguna norma de programación enviará un aviso a la empresa privada y la invitará a rectificar, pudiendo llegar a revocar la concesión en caso de no atender al aviso ${ }^{245}$. No obstante, la falta de eficacia del control por parte de las Instituciones de los Medios ha sido objeto de constantes críticas en los últimos años ${ }^{246}$. Se ha criticado duramente la influencia de intereses políticos y económicos de los Länder a la hora de imponer una sanción ${ }^{247}$.

\section{A) El control funanciero: el Tribunal de Cuentas y la KEF}

En relación con el sector público, en cuanto al control financiero, además del ejercido por las propias Instituciones, el control externo lo lleva el Tribunal de Cuentas, que debe enviar al Consejo de Radiotelevisión las conclusiones de la auditoría que realice sobre la actividad de la Institución para que éste las considere a la hora de aprobar las cuentas anuales presentadas por el Intendente. El control de la actividad económica que realiza el Tribunal de Cuentas será un control jurídico y no político o de oportunidad, y, por otro lado, se trata de un control subsidiario y complementario al control interno que sobre el Intendente realizan tanto el Consejo de Radiotelevisión como el de Administración. Además, el control del Tribunal de Cuentas puede ser recurrido ante los órganos judiciales correspondientes, y el resultado de su actividad sólo será conocido por la propia Institución y por el Gobierno, que es quien en definitiva tiene que procurar la garantía de la libertad de los medios ${ }^{248}$.

242 Vid. BVerfGE 73, 118 (163 y 183); y también, § 41 RStV.

243 BVerfGE 73, 118 (164), o «cuarta» BVerfGE, que permite la existencia del sistema dual siempre que se garantice la función pública.

$244 \S 49 R S t V$. El catálogo establecido recoge unas 57 infracciones, como emitir sin concesión, incumplir la normativa sobre programación, sobre publicidad, o sobre protección de la juventud y de datos personales. Estas infracciones pueden ser sancionadas con multas desde los 50.000 hasta los 500.000 euros y con privación de libertad (por periodos de seis meses) si se trata del incumplimiento de normas de protección de la juventud.

245 Por ejemplo, vid. § 51.(5) LMedienG; y $\$ 33$ BremLMG.

246 En relación con la presión ejercida por algunas Instituciones de los Medios que han amenazado con trasladarse a otro Land que tuviera sanciones menos estrictas, vid. NigGERMEIER, S./SCHADER, P., «Schafft die Landesmedienanstalten ab!», en Frankfurter Allgemeine Zeitung.net, de 20 de marzo de 2005.

247 Poptcheva, E.V., «Las autoridades independientes...», op. cit., pp. 300-302. SaarLG).

248 No obstante, en Bayern y en Saarland se informa también al Parlamento (art. 13 BayR-G y $\$ 40$ 
Respecto del control financiero del sector público, debemos destacar la existencia de una Comisión encargada de determinar las necesidades financieras de los organismos de radiotelevisión (Kommission zur Ermittlung des Finanzbedarfs der Rundfunkanstalten, $K E F)^{249}$. La KEF surge fruto del pronunciamiento del Tribunal Constitucional federal alemán sobre la necesidad de garantizar la independencia económica de las Instituciones de Radiotelevisión para proteger la libertad de los medios de comunicación ${ }^{250}$, y así se regula por primera vez en la Tercera modificación del $R S t V^{251}$. Se compone de 16 expertos independientes nombrados por el Gobierno de cada Land, por un periodo de cinco años con la posibilidad de reelección. Es la propia Comisión la que elige a su Presidente ${ }^{252}$. Su objetivo es garantizar la autonomía financiera de las emisoras de radiotelevisión y para ello comprueba las necesidades financieras de las Instituciones en función de la política financiera seguida por las mismas ${ }^{253}$. La KEF informa a los Gobiernos de los Länder, cada dos años, de la situación financiera de las Instituciones de Radiotelevisión y concreta qué cantidad se necesita modificar del porcentaje recibido de la contribución por radiotelevisión, así como el porcentaje que corresponde a cada Institución de Radiotelevisión ${ }^{254}$.

Por su parte, en relación con los controles externos de la televisión privada, como en la pública, podemos diferenciar entre un control económico y otro jurídico. La Institución tiene completa autonomía respecto de su régimen financiero y la gestión de sus recursos. En este caso, el control de la gestión económica está ejercido por el Tribunal de Cuentas del Land, que comprueba que el ejercicio económico se corresponde con lo dispuesto en las normas y en los principios que deben inspirar la actuación de la Institución ${ }^{255}$. Y, por lo que se refiere al control externo jurídico, el control estatal no puede consistir más que en fiscalizar si la actividad de la Intitución se desarrolla o no conforme a lo establecido en las normas jurídicas, no en juicios de oportunidad ${ }^{256}$.

\section{B) El control de la programación: licencias y contenido}

En el ámbito público, el control de la programación de las Instituciones de los Medios se centrará en comprobar que cumplen los requisitos legales, no tanto

249 Vid. http://www.kef-online.de/ (Consultado: 06/07/2015).

$250 \mathrm{Al}$ respecto vid. la «octava» BVerfGE 90, 60, de 22 de febrero de 1994.

251 Staatsvertrag über den Rundfunk im vereinten Deutschland - Rundfunkstaatsvertrag (RStV), de 31 de agosto de 1991, en la redacción de la Tercera modificación, del 26 de agosto al 11 de septiembre de 1996. En la actualidad, $\S 14 R S t V$. Y sobre su establecimiento, vid. $\S 2$ Rundfunkfinanzierungstaatsvertrag, RfinStV.

$252 \S 4$ Rundfunkfinanzierungstaatsvertrag, RfinStV.

253 § Rundfunkfinanzierungstaatsvertrag, RfinSt V.

$254 \S \S 5$ a 7, 8 y 10 Rundfunkfinanzierungstaatsvertrag, RfinStV.

$255 \S$ 61.(8) SMG y $\$$ 54.(5) BremLMG.

256 Así se establece, entre otros, en el art. 19 BayMG; y $\$ 55$ BremLMG. 
en la autonomía de la emisora. El problema que nos vamos a encontrar con el control de la programación se derivará de la estructura federal del país y, por otro lado, del alcance nacional de las emisoras privadas. Por este motivo, con el fin de coordinar la actuación de las Instituciones de los Medios se creó la ya citada Conferencia de Directores de las Instituciones de los Medios (Direktorenkonferenz der Landesmedienanstalten, DLM), cuya misión principal es, entre otras, establecer las Directrices de las Instituciones para la aplicación de las reglas de publicidad y la protección de la juventud en la programación radiotelevisiva. Asimismo, dentro de la organización de las Instituciones de Radiotelevisión y de los Medios existen unos Consejos de Programación encargados de asesorar a la Institución sobre la programación $^{257}$.

a) La creación de nuevos programas: la $Z A K$ y el Drei Stufen Test

A la hora de conceder licencias para la emisión de nuevos programas, eran las Instituciones de los Medios las competentes de este aspecto, siendo una Comisión la encargada de su supervisión: la Comisión de Licencias y Supervisión (Kommission für Zulassung und $A$ ufsicht, $Z A K)^{258}$. Todas las radios y televisiones privadas que quieran emitir un nuevo programa requerirán de la correspondiente autorización, con la excepción de las radios con emisión exclusiva por Internet. Se ocupa incluso de los servicios telemedia ${ }^{259}$. La ZAK está integradas por los representantes legales de las catorce Instituciones de los Medios. Será Presidente de la ZAK el Director de la emisora correspondiente que ostente el cargo. Sus funciones se centran en la supervisión de la concesión de licencias ${ }^{260}$.

En este punto debemos recordar que con el fin de comprobar que los nuevos programas fruto del uso de las nuevas tecnologías van a respetar el pluralismo, a partir del año 2009 se exige que superen el denominado «Test de los Tres Niveles» (Drei Stufen Test). Dicho Test fue introducido con la aprobación el 19 de diciembre de 2008, de la Duodécima revisión del Acuerdo federal de Radiotelevisión $(R S t V)$ ante las críticas que la televisión pública estaba recibiendo por el hecho de estar elaborando los mismos programas que las privadas — lo que llevó a plantearse la conveniencia de mantener o no la financiación de las mismas a través de la tasa pública—. Este Test consiste en analizar: primero, si el programa es necesario social, cultural y democráticamente; segundo, si el programa contri-

257 Asi, el ARD-Programmbeirat ( $\$ 2$ y $7 R S t V$; y $§ 5 .{ }^{\text {a }} .3$ ARD-Satzung); o el Programmbeirat previsto para las Instituciones de los Medios y cuyos miembros serán nombrados por el Gerente de la emisora ( $\$ 32$ $R S t V)$.

$258 \& 35 R S t V$.

$259 \S 20 \mathrm{~b} R \mathrm{R} t \mathrm{~V}$.

$260 \S 36 .(2) R S t V$. 
buye a la competitividad publicitaria; y, tercero, cuál es el coste financiero que supone dicho programa ${ }^{261}$.

b) Los contenidos: la KJM y la FSF

En el segundo caso, sobre el contenido de la programación, además de asegurarse que la misma contribuye al pluralismo y a la formación de una opinión pública libre, se pretende garantizar que la misma no lesiona derechos fundamentales y, en concreto, los derechos de los menores. Incluso se ha establecido la obligación de que las Instituciones de Radiotelevisión nombren un «Delegado de Protección de la Juventud» para que vele por los derechos de los menores en el terreno mediáti$\mathrm{Co}^{262}$. En este sentido, en el sector privado, con el fin de evitar un impacto perjudicial en los menores por los programas emitidos, se constituye la Comisión para la protección de la juventud en los medios (Kommission für Jugendmedienschutz, KJM) ${ }^{263}$. La KJM se compone de 12 miembros, siendo 6 de las Instituciones de los Medios, 4 representando a las instituciones estatales en defensa de la juventud, y 2 expertos a nivel federal, y está presidido por el Director de una de las Instituciones de los Medios $^{264}$. No se podrá ser miembro, a la vez, de la $K J M$ y de la $K E K^{265}$, y en ningún caso podrán formar de la KJM, entre otros, los miembros de las Instituciones de Radiotelevisión de la ARD, de la ZDF o de Deutschlandradio, así como del canal ARTE o las emisoras privadas o servidores de telemedia asociados a ellas ${ }^{266}$. Su tarea es proteger a la juventud y a la infancia del aspecto más negativo de la programación, respetando el Acuerdo sobre defensa de dignidad y la juventud en radiotelevisión y telemedia (Jugendmedienschutz-Staatsvertrag - JMStV) ${ }^{267}$.

261 Vid. § 11f.4 RStV; y, también, PoptcheVA, E.V., «Las autoridades independientes...», op. cit., p. 296; y Lilienthal, V., «Integration als Programmauftrag», en APuZ, n. ${ }^{\circ}$ 9-10, 2009, pp. 8-9 (pp. 6-11).

$262 \S 7$ Jugendmedienschutz-Staatsvertrag - JMSt $V$, donde se establece la excepción para aquellos servicios telemedia con menos de 50 empleados o aquellas emisoras que no tengan difusión a nivel nacional, siempre que se adhieran a una organización de autocontrol voluntario como la Freiwillige Selbstkontrolle Fernsehen (FSF).

263 Vid. http://www.kjm-online.de/recht/gesetze-und-staatsvertraege/jugendmedienschutz-staatsvertrag-jmstv.html (Consultado: 06/07/2015); y § 35.(2) RStV.

$264 \$ 14 .(3)$ Jugendmedienschutz-Staatsvertrag - JMStV.

$265 \$ 35 .(6) R S t V$.

$266 \S 14 .(4)$ Jugendmedienschutz-Staatsvertrag - JMStV; y $\$ 28 R S t V$.

267 Sobre la protección de la juventud, vid. la Ley de Protección de la Juventud (Jugendschutzgesetz, $J u S c h G$ ), de 23 de julio de 2002, modificada por última vez el 7 de agosto de 2013 (\$§ 11 a 16). Y en relación con los medios de comunicación, vid. Acuerdo sobre la defensa de dignidad y la juventud en la radiotelevisión y telemedia (Staatsvertrag über den Schutz der Menschenwürde und den Jugendschutz in Rundfunk und Telemedien (Jugendmedienschutz-Staatsvertrag — JMStV), de 10 al 27 de septiembre de 2002, ultima modificación el 30 de octubre de 2009 (entrada en vigor el 1 de abril de 2010). Y en relación con su tratamiento por parte de los medios de comunicación, $\$ \S 11$ a $25 \mathrm{RSt} \mathrm{V}$, creándose la Oficina federal para la inspección de los medios de comunicación que ponen en peligro a los menores (Bundesprüfstelle für jugendgefährdende Medien) ( $\$ 18$ RStV), encargada de controlar y vigilar los medios de comunicación. Por último, desarrollando las citadas previsiones legales, vid. 
Por último, por parte del sector privado, y con el fin de controlar el contenido de la programación, destaca la existencia de la Asociación del Autocontrol Voluntario de la Televisión (Freiwillige Selbstkontrolle Fernsehen, FSF) ${ }^{268}$. La FSF es el único órgano de autocontrol voluntario en el ámbito de los medios de comunicación de titularidad privada ${ }^{269}$. Fue creada con la finalidad de controlar el aumento de violencia que en los años noventa se estaba produciendo en la televisión privada. La FSF está compuesta por miembros que se organizan en una Asamblea General y en un Consejo ejecutivo ${ }^{270}$. Cuenta, además, con un Consejo de Administración formado entre 10 y 18 miembros expertos en Derecho de los medios de comunicación ${ }^{271}$. Su función consiste en examinar si los programas de televisión respetan los principios informativos y no atentan contra la integridad de la juventud $^{272}$. Pero la FSF sólo va a examinar aquellos programas que los medios de comunicación sometan a su control, ya que, en todo caso, la decisión que adopte dicha Asociación será sometida posteriormente a la ya citada KJM. A pesar de las iniciativas llevadas a cabo por esta Asociación, su falta de competencia sancionadora resta eficacia a sus pronunciamientos.

C) El control de la publicidad: el Deutscher Werberat, $D W$

En relación con la publicidad, en el modelo alemán está limitada su emisión ${ }^{273}$. En todo caso, se prohíbe la publicidad encubierta — de ahí que los comerciales deban identificarse- ${ }^{274} \mathrm{o}$ aquélla que induzca a error o perjudique a los consumidores, a su salud y a su seguridad ${ }^{275}$. Sin embargo, se permite la publicidad política, filosófica o religiosa ${ }^{276}$. Asimismo, el patrocino está permitido, excepto durante las noticias y programas de actualidad ${ }^{277}$.

las Directrices comunes de las Instituciones de los Medios para garantizar la defensa de la dignidad y la juventud (Gemeinsame Richtlinien der Landesmedienanstaltenzur Gewährleistung des Schutzes der Menschenwürde und des Jugendschutzes (Jugendschutzrichtlinien - JuSchRiL), de 8 y 9 de mayo de 2005.

268 Vid. http://fsf.de/ (Consultado: 06/07/2015); y, § 19 Jugendmedienschutz-Staatsvertrag - JMStV, así como sus Estatutos (Satzung der Freiwillige Selbstkontrolle Fernsehen), de 28 de febrero de 2012. Sobre esta Asociación, vid. PoptCHEva, E.V., «Las autoridades independientes...», op. cit., pp. 302-303; y GoTTBERG, J. Von, «Die Freiwillige Selbstkontrolle Fernsehen (FSF)», en BAum, A./LANGEnbuCher, R.L./PöTtKer, H./ScHICHA, CH. (eds.), Handbuch Medienselbstkontrolle, VS Verlag, Wiesbaden, 2005, pp. 375-418.

269 Reglamento de la Freiwillige Selbstkontrolle Fernsehen (Prüfordnung der freiwilligen selbstkontrolle Fernsehen, PrO-FSF), de 14 de febrero de 2014.

$270 \S \S 9$ a 12 Satzung der Freiwillige Selbstkontrolle Fernsehen.

$271 \S \S 3$ a 5 Satzung der Freiwillige Selbstkontrolle Fernsehen.

272 § 2 Satzung der Freiwillige Selbstkontrolle Fernsehen. $45 \mathrm{RStV}$

273 Limitando el tiempo de emisión a un máximo del 20\% de la programación, vid. $\$$ 15, 16 y 44,

$274 \S$ 7.(3) y 7.(6) RStV.

$275 \$ 7 .(1) R S t V$.

$276 \$ 7 .(9) R S t V$.

$277 \S 8 .(6) R S t V$. 
Con el fin de garantizar unos principios comunes para la emisión de publicidad en el sector privado, se han elaborado unas Directrices para la radiotelevi$\operatorname{sión}^{278}$. La idea es no interferir con las emisiones de televisión, teniendo en cuenta las pausas naturales de transmisión y la duración y naturaleza del programa ${ }^{279}$. Así, por ejemplo, en películas (al margen de series y documentales) y noticias no podrá haber publicidad antes de, al menos, 30 minutos de programación; y en programas infantiles no habrá ningún tipo de interrupción ${ }^{280}$.

Teniendo en cuenta que la regulación de la publicidad en Alemania sigue un modelo dual basado, por un lado, en las reglas legalmente establecidas por el $R S t V$ y, por otro lado, en el sistema de la autoregulación, debemos citar aquí un órgano encargado de esta misión. Con carácter transversal a todos los medios de comunicación social analizados, y con el fin de evitar una manipulacion de la industria publicitaria, en 1972 se creó el Consejo de Publicidad de Alemania (Deutscher Werberat, $D W$ ) para la autorregulación y autocontrol de la publicidad $^{281}$. El Consejo está integrado por 40 miembros. Entre las competencias del $D W$, a pesar de no tener competencia para analizar la vulneración de las normas vigentes, podrá adoptar Recomendaciones de comportamiento ético por parte de la prensa en determinados sectores (como pueden ser la discriminación, la proteccion de los menores, la publicidad de alimentos...), así como la posibilidad de realizar un «reproche público» y requerir a la empresa de comunicación correspondiente que retire una determinada publicidad. A pesar de todo, el Consejo se centra en la publicidad comercial, quedando al márgen la publicidad relacionada con los partidos políticos o con asociaciones de carácter religioso.

D) El control de las normas anticoncentración: la KEK

Es en el sector privado, más que en el público, donde las medidas anticoncentración juegan un papel más activo. El crecimiento de Internet y la globalización permiten la circulación de los servicios audiovisuales al márgen de todo tipo

278 Directrices comunes para las Instituciones de los Medios sobre publicidad, distinción entre publicidad y programación y sponsoring y teleshopping, en la radio (Gemeinsame Richtlinien der Landesmedienanstalten für die Werbung, zur Durchfübrung der Trennung von Werbung und Programm und für das Sponsoring sowie Teleshopping im Hörfunk (WerbeRL/HÖRFUNK), de 23 de febrero de 2010; y Directrices comunes, pero para el campo de la televisión (Gemeinsame Richtlinien der Landesmedienanstalten für die Werbung, die Produktplatzierung, das Sponsoring und das Teleshopping im Fernsehen (WerbeRL/FERNSEHEN), de 23 de febrero de 2010. La base jurídica de dichas Directrices se encuentra en $\S \S 46 R S t V$ en relación con los $\S \S 7,7 \mathrm{a}, 8,8 \mathrm{a}, 44,45$ y $45 \mathrm{a}$ $R S t V$.

$279 \S 7 \mathrm{a} .(2) R S t V$.

$280 § 7 \mathrm{a} .(1)$ y 7a.(3) $R S t V$.

$281 \mathrm{Al}$ respecto, vid. https://www.werberat.de/ (Consultado: 06/07/2015). Sobre el Werberat, vid. Poptcheva, E.V., «Las autoridades independientes...», op. cit., pp. 308-309. 
de fronteras: las concentraciones ya no sólo se producen a nivel nacional, sino también internacional ${ }^{282}$.

En este terreno, el modelo alemán se asemeja bastante al modelo anglosajón. Así se ha fijado el criterio de la cuota de audiencia para determinar cuándo una concentración resulta perjudicial para el pluralismo informativo. Así, se considerará que si un operador domina el $30 \%$ de la audiencia o un porcentaje algo menor, pero al mismo tiempo tiene una presencia relevante en otros sectores de la comunicación, hay un problema de concentración. Así, un operador podrá controlar un número ilimitado de canales simpre y cuando no se den las citadas circunstancias. Si aún así se mantuviera la situación, otra peculiaridad del modelo alemán es la posibilidad que se ofrece al operador que alcanza una determinada posición dominante, de vender activos o dar entrada en su programación a un operador independiente por un determinado periodo de tiempo, o bien, crear un Consejo asesor de programación en el que han de estar representados los grupos sociales y políticos más significativos ${ }^{283}$.

Este control de las concentraciones también se hace por las Insticuiones de los Medios, que fiscalizan el cumplimiento por parte de las empresas concesionarias de las medidas anticoncentracion y cuentan, para ello, con la colaboración de la Comisión para el seguimiento de la concentración en el ámbito de los medios (Kommission zur Ermittlung der Konzentration in Medienberiech, KEK) ${ }^{284}$. La KEK es un organismo independiente creado para controlar la posición de las diferentes empresas privadas que existen en el mercado de los medios. Se compone de 12 expertos independientes, tal y como dispone el $R S t V^{285}$. Su Director será nombrado de entre los Directores de la $A L M$, esto es, de entre los Directores de las Instituciones de los Medios, por un periodo de dos años ${ }^{286}$. Como órgano de apoyo a la KEK, del seno de las Instituciones de los Medios surge la ya citada Conferencia de Directores $(D L M)$ para colaborar en el ejercicio de esta función ${ }^{287}$. Para facilitar la labor de estos organismos, el $R S t V$ establece una serie de obligaciones de información que deben cumplir las empresas privadas de televisión ${ }^{288}$. Para que la KEK entre en escena se lo debe solicitar previamente una Institución de los Medios y entonces la KEK actúa conforme al procedimiento previsto legalmente,

282 Sobre concentración diagonal o crossmedial, vid. ROMERo DomínguEZ, L.R., «Monopolio y pluralismo. Claves para armonizar la concentración mediática y el control institucional en Alemania», en Revista Latina de la Comunicación Social, n. ${ }^{\circ}$ 64, 2009, p. 542; y DOYLE, G., «Economía audiovisual:...», op. cit., p. 16. Y también, Bomas, W., «Der duale Rundfunk...», op. cit., pp. 35-46.

283 GonZÁlez ENCINAR, J.J., «Modelos comparados...», op. cit., p. 105.

284 Vid. http://www.kek-online.de/ (Consultado: 06/07/2015); y § 36.(4) RStV. Y sobre su regulación, vid. las Reglas de procedimiento de la KEK (Geschäftsordnung für die Kommission zur Ermittlung der Konzentration im Medienbereich (KEK)), de 16 de junio de 1997, modificado por última vez el 11 de febrero de 2014.

$285 \$ 35 .(5) R S t V$.

$286 \S \S 1$ a 5 Geschäftsordnung für die Kommission zur Ermittlung der Konzentration im Medienbereich (KEK).

$287 \S \S 35$ a 37 RStV.

$288 \S \S 22$ y $23 R S t V$. 
siendo el argumento principal la cuota de audiencia ${ }^{289}$. Se debe realizar aquí un triple control analizando tres conceptos, esto es, la fuerza de la sugestión (la capacidad de penetación en la audiencia), los efectos de la difusión (la capacidad para llegar a emitir según la disponiblidad técnica), y la actualidad (la inmediatez informativa que pueda ofrecer $)^{290}$. Los casos de concentración que puedan llegar a producirse son mínimos. Así, por ejemplo, podemos citar el conocido caso del grupo periodístico alemán Axel Springer $A G$ que en el año 2006 renunció a sus pretensiones por hacerse con la cadena privada ProSiebenSat ${ }^{291}$. Pero no faltan voces que proponen otra forma de calcular la concentración debido, especialmente, al proceso de internacionalización entre las empresas mediáticas ${ }^{292}$.

El terreno que más se ha visto afectado por la concentración ha sido el sector radiofónico. Ya hemos visto cómo el mercado de la radio está muy fragmentado, con un elevadísimo número de radios privadas frente a las públicas, y con una cobertura más regional o local que dificulta el lanzamiento de campañas a nivel nacional, lo cual, como es lógico, repercute en las ventas de publicidad, esto es, en su financiación ${ }^{293}$. En cualquier caso, y quizá por referirnos a Alemania, no existe un verdadero problema de concentración de medios. Mientras la regla general en la mayoría del sector europeo es la concentracion de las cuotas de mercado en muy pocos operadores, en Alemania el liderazgo por la mayor cuota de mercado está muy repartido, dado el gran número de canales existentes ${ }^{294}$.

$$
* * *
$$

\section{TITLE: Status of the media in Germany}

ABSTRACT: The guarantee of pluralism and the formation of a free public opinion take their maximum expression in the German model of legal regulation of the media. After the dramatic experience of the Second World War, Germany assumed as an essential element of its democratic structure the guarantee freedom of the media, in order to avoid manipulation by public authorities and to protect the formation of a Free public opinion, shows of the existing social, economic and political pluralism in the new German society. The model of media regulation created for this purpose, based on a dual system of broadcasting, with the requirement of institutions with an organization and a democratic functioning and a system of «mixed" financing, as well

$289 \S 3$ Rfinst V

290 Sobre esta cuestión, vid. Romero Domínguez, L.R., «Monopolio y pluralismo...», op. cit., pp. $545-546$

291 Con un detallado anális, vid. Romero Domínguez, L.R., «Monopolio y pluralismo...», op. cit., pp. 540-552. Vid., también, §§ 35-43 Ley contra las Restricciones de la Competencia, de 26 de agosto de 1998 (Gesetz gegen Wettbewerbsbeschränkungen, GWB), modificada por última vez el 31 de agosto de 2015; y $\$$ $36 \mathrm{RStV}$. Con referencia a los dos grandes grupos, Kinch Group y Bertelsmann, vid. Krotz. K., «De-The Radio...», op. cit., pp. 126-127.

292 Por ejemplo, art. 27 RStV. Vid., Goulanakis, G./Zagouras, G., «Plädoyer für ein europäisches Medienkonzentrationsrecht», en Zeitschrift für Medien- und Urbeberrecht, n. ${ }^{\circ}$ 10, 2004, pp. 716-725.

293 Bomas, W., «Der duale Rundfunk...», op. cit., p. 33; y HüLSEN, I., «Radiosender kämpfen um Werbeanteile», en Financial Times Deutschland, de 1 de febrero de 2005, p. 5.

294 Camáñez, G.C., «Televisión en Europa:...», op. cit., p. 337; y Hoffmann-Riem, W./Schulz, W., «La televisión pública...», op. cit., pp. 63-64. 
as an essential intervention of the German Federal Constitutional Court in this process, acting as a guarantor of pluralism, make Germany a reference to the independence of the media facing the Government and other public authorities.

RESUMEN: La garantía del pluralismo y de la formación de una opinión pública libre cobran su máxima expresión en el modelo alemán de regulación jurídica de los medios de comunicación. Tras la dramática experiencia de la Segunda Guerra Mundial, Alemania asumió como elemento esencial de su estructura democrática la garantía de la libertad de los medios de comunicación, con el fin de evitar su manipulación por parte de los poderes públicos y proteger así la formación de una opinión pública libre, muestra del pluralismo social, económico y político existente en la nueva sociedad alemana. El modelo de regulación mediática creado a tal efecto, basado en un sistema dual de radiotelevisión, con la exigencia de unas instituciones con una organización y un funcionamiento democrático y un sistema de financiación «mixto», así como una intervención esencial del Tribunal Constitucional Federal alemán en este proceso, actuando como garante del pluralismo, convierten a Alemania en un referente de la independencia de los medios de comunicación frente al Gobierno y resto de poderes públicos.

KeY words: Pluralism, Public opinion, Media, Radio, Press, Television, Dual system.

Palabras clave: Pluralismo, opinión pública, Medios de comunicación, Radio, Prensa, Televisión, Sistema dual.

FECHA DE RECEPCIÓN: 01.09.2015

FECHA DE ACEPTACIÓN: 01.10.2015 